\title{
Anti-Infective, Anti-Inflammatory, and Immunomodulatory Properties of Breast Milk Factors for the Protection of Infants in the Pandemic From COVID-19
}

\section{Pasqua Anna Quitadamo*, Laura Comegna and Pierpaolo Cristalli \\ NICU "Casa Sollievo della Sofferenza" Foundation, Scientific Research and Care Institute, San Giovanni Rotondo, Italy}

OPEN ACCESS

Edited by:

Ana Afonso,

University of São Paulo, Brazi

Reviewed by:

Aruni Wilson,

Loma Linda University, United States

Luigi Rosa,

Sapienza University of Rome, Italy

*Correspondence:

Pasqua Anna Quitadamo

pasquaq@tiscali.it

Specialty section

This article was submitted to Infectious Diseases - Surveillance,

Prevention and Treatment,

a section of the journal

Frontiers in Public Health

Received: 31 July 2020 Accepted: 30 November 2020

Published: 02 March 2021

Citation:

Quitadamo PA, Comegna $L$ and Cristalli P (2021) Anti-Infective,

Anti-Inflammatory, and

Immunomodulatory Properties of Breast Milk Factors for the Protection

of Infants in the Pandemic From

COVID-19.

Front. Public Health 8:589736.

doi: 10.3389/fpubh.2020.589736
COVID-19 pandemic since the end of 2019 spreads worldwide, counting millions of victims. The viral invasion, systemic inflammation, and consequent organ failure are the gravest features of coronavirus disease 2019 (COVID-19), and they are associated with a high mortality rate. The aim of this study is to evaluate the role of breast milk in the COVID-19 pandemic, analyzing its antiviral, anti-inflammatory, and immunoregulatory effects due to its bioactive components, so numerous and important for the protection of infants. The study tried to demonstrate that all the components of human milk are capable of performing functions on all the pathogenic events recognized and described in COVID-19 disease. Those human milk factors are well-tolerated and practically free of side effects, so breast milk should become a research topic to discover therapies even in this epidemic. In the first part, the mechanisms of protection and defense of the breast milk elements will be delineated; in the second section, it will describe the human milk effects in viral infections and it will be hypothesized how the known mechanisms could act in COVID infection.

Keywords: antiviral activity, functions human milk factors, COVID 19, clinical application of human milk factors, human milk research

\section{HIGHLIGHTS}

- To protect infants and newborns from COVID-19, they would be fed breast milk. Where mother's milk is not available, or for fragile babies (premature or newborns with pathologies), the alternative must be represented by human milk donated to the Human Milk Banks, which, although pasteurized, retains most of its anti-infectious properties (e.g., total savings of human milk oligosaccharides and fatty acids). Whenever human milk substitutes are needed, formulas added to milk bioactive factors should be preferred.

- Human milk factors are well-tolerated and practically free of side effects, so breast milk should become a research topic aimed to identify therapies even in this epidemic. 
- Many components of human milk may have a potential therapeutic activity, and they are under evaluation in infections, inflammatory bowel diseases, hypertension, cognitive decline, and cancer. Most of the bioactive factors of human milk may interact synergistically with each other or with the immune response. During this study, we tried to demonstrate that human milk mediators might have a function in all events recognized and described in COVID-19.

\section{INTRODUCTION}

Since the end of 2019, an acute severe viral infection has emerged with rapid transmission around the world to over a million people within a few months. Named coronavirus disease 2019 (COVID-19) by the World Health Organization, the pandemic disease has resulted in one of the largest global public health problems in modern history. Severe acute respiratory syndrome coronavirus 2 (SARS-CoV-2) infects cells in the respiratory system and causes inflammation and cell death. Subsequently, the virus spreads out and damages other vital organs and tissues, triggering a complicated spectrum of pathophysiological changes and symptoms. Systemic inflammation and consequent respiratory, circulatory, and renal failure are the severe features of COVID-19 and are associated with a very high mortality rate. Given the lack of vaccine and antiviral therapy and the non-existent herd immunity, there is an urgent need to find therapeutic solutions to stop the spread of the infection and to effectively treat the disease; this is the highest priority among health care providers, government authorities, and pharmaceutical industry.

Abbreviations: SARS-CoV-2, severe acute respiratory syndrome-coronavirus 2; SIgA, secretory IgA; SIgM, secretory IgM; HMO, human milk oligosaccharides; 20-FL, 20-fucosyllactose; 30-SL, 30-sialyllactose; 60-SL, 60-sialyllactose; LNnT, lacto-N-neotetraose; AIEC, adherent-invasive Escherichia coli; LNT, lacto-Ntetraose; SCFA, short-chain fatty acid; CD4+ and CD8, T lymphocytes; Treg, regulatory T cells; NF-кB, nuclear factor kappa Beta; TLR, toll-like receptor; IL, Interleukin; PAMP, pathogen-associated molecular pathways; PNC, plateletneutrophil complex; IFN $\gamma$, interferon $\gamma$; TNF, tumor necrosis factor; TGF, transforming growth factor; G-CSF, granulocyte colony-stimulating factor; $\mathrm{M}$ CS, macrophage colony-stimulating factor; GM-CSF, granulocyte macrophage colony-stimulating factor; IL-1RA, IL-1 receptor antagonist; NEC, necrotizing enterocolitis; Th1, T helper type 1; Th2, T helper type 2; NK, natural killer; TGF- $\beta$, transforming growth factor $\beta$; FOXP3, forkhead box P3; EGF, epidermal growth factor; HB-EGF, heparin-binding epidermal growth factor-like growth factor; VEGF, vascular endothelial growth factor; CXC, chemokines; SFA, saturated fatty acid; MUFA, monounsaturated fatty acid; PUFA, polyunsaturated fatty acid; PPAR, peroxisome proliferator-activated receptor; PAF, platelet-activating factor; COX-2, cyclooxygenase 2; SPM, specialized pro-resolving mediator; FFA, free fatty acid; pIgR, polymeric immunoglobulin receptor; LF, lactoferrin; LBP, lipopolysaccharide binding protein; ICAM-1, intercellular adhesion molecule 1; CD54, cluster of differentiation 54; HBD, human $\beta$-defensin; OPN, osteopontin; ROP, retinopathy of prematurity; ROS, reactive oxygen species; SOD, superoxide dismutase; GPx, glutathione peroxidase; miRNA, microRNA; DC, dendritic cell; RSV, respiratory syncytial virus; HBGA, histo-blood group antigens; PGE, prostaglandins; MERS, Middle East respiratory syndrome; IUGR, intrauterine growth restriction; WHO, World Health Organization; CDC, Centers for Disease Control and Prevention; AAP, American Academy of Pediatrics; ACE-2, angiotensin-converting enzyme 2; RBD, receptor-binding domain; TMPRSS, type II transmembrane serine protease; LNFP III, lacto- $N$-fucopentaose III; sTLR, soluble Toll-like receptor; $\mathrm{sCD}$, soluble cluster of differentiation; MFG-E8, milk fat globule-epidermal growth factorfactor VIII.
For more than 20 years, the protective power of breast milk has been known against many diseases and with special regard to infections due to its richness in immune-related factors like human milk oligosaccharides, milk proteins and lipids, and other active mediators (see section Breast Milk and Mediators and Breast Milk and Viral Infection).

Undoubtedly, this breast milk power can be ascribed to the large number of bioactive molecules that have been proven to be protective against infections, bringing down inflammation, facilitating immune system and organ growth, and influencing the infant microbiome, at a developmental stage where the infant's own immune system is relatively immature and naive (see sections Breast Milk and Mediators and Breast Milk and Viral Infection).

Nowadays, with the increased phenomenon of antibiotic resistance, national and international research has the purpose to discover new antibiotics or natural substances that can act as antibiotics. Breast milk has become the subject of many of these researches and on others about inflammatory diseases, cancer, and other pathologies. Preclinical investigations on human milk are translating into clinical applications, up to the large-scale production of the active molecules derived from it (1).

The aim of this study is to evaluate the role of breast milk in the COVID-19 pandemic, analyzing its antiviral, antiinflammatory, and immunoregulatory effects due to the bioactive components. Few data are available about the human milk's potential role against COVID-19, but a lot of studies documented its antiviral effect against many viruses. The following is a brief recap of the current evidence on the mechanisms that explain its multiple functions in the context of anti-infective responses to deduce the possible practical application of breast milk against this pandemic.

In the first part, the known mechanisms of protection and defense of the individual elements contained in breast milk will be delineated (Table 1), while in the second section, human milk effects in viral infections will be described.

In the last part, it will be hypothesized how these mechanisms could counteract COVID-19 infection in its different stages starting from the knowledge that has currently been acquired about this new epidemic.

\section{BREAST MILK AND MEDIATORS}

The human milk interacts with the newborn's gut to increase the immune response against infection, and it can be considered like an immune system that includes many immunomodulatory mediators. It is known that human milk changes its immunological constituents related to the time from the delivery and maybe to the nutritional state of the mother. Recently, some authors suggest that there is modification also to response to the active needs of the nursing baby $(2,3)$. Riskin et al. (4) have shown in their study that the total number of white blood cells increases in human milk in relation to nursing infant's infection, specially the number of macrophages; so, the study underlines the immunological role of human milk. 


\begin{tabular}{|c|c|c|c|c|c|}
\hline & Antiviral & Antinflammatory & Immunomodulation & Anticoagulant & Repair of the damage \\
\hline $\begin{array}{l}\mathrm{HMO} \\
>20 \mathrm{~g} / \mathrm{L} \text { in colostrum } \\
12 \mathrm{~g} / \mathrm{L} \text { in mature milk }\end{array}$ & $\begin{array}{l}\text { Direct: inhibiting the adhesion of } \\
\text { pathogens } \\
\text { Indirect: act as a soluble analog of the } \\
\text { receptor for pathogens, prebiotics }\end{array}$ & $\begin{array}{l}\text { Prevent and decrease inflammatory response } \\
\text { Inhibit interferon production } \\
\text { Suppress activation of the NF-kB } \\
\text { Inhibit the adhesion of leukocytes to the } \\
\text { endothelium triggering inflammatory pathway } \\
\text { Suppress the infiltration of leukocytes } \\
\text { Decrease acute phase inflammatory cytokine } \\
\text { secretion } \\
\text { Promote healthy intestinal microbiota } \\
\text { Regulate commensal bacteria with } \\
\text { antinflammatory response }\end{array}$ & $\begin{array}{l}\text { Promote the maturation of the immune } \\
\text { system } \\
\text { Create a more balanced Th1/Th2 cytokine } \\
\text { response } \\
\text { Modulate immune signaling pathways, } \\
\text { including TLR3, TLR5, PAMP }\end{array}$ & & $\begin{array}{l}\text { Stimulate maturation of } \\
\text { epithelial cells }\end{array}$ \\
\hline \multicolumn{6}{|l|}{ Cytokines } \\
\hline $\mathrm{IL} 1 \beta$ & & $\begin{array}{l}\text { Attenuates the activation of pro-inflammatory } \\
\text { IL-8 }(1.2 \mathrm{ng} / \mathrm{L})\end{array}$ & $\begin{array}{l}\text { Suppresses proinflammatory responses of } \\
\text { NF-kB signaling }\end{array}$ & & \\
\hline $\begin{array}{l}\text { IL-1RA } \\
\text { IL-1 receptor antagonist }\end{array}$ & & $\begin{array}{l}\text { Competes with the pro-inflammatory cytokine, } \\
\text { IL-1, for receptor binding }\end{array}$ & & & \\
\hline $\mathrm{IL}-2$ & & & $\begin{array}{l}\text { Recruits T cell to stimulate an } \\
\text { antigen-specific immune response } \\
\text { Play an important role in the differentiation of } \\
\text { neonatal T cells toward a preferential Th1, } \\
\text { rather than Th2 }\end{array}$ & & $\begin{array}{l}\text { Stimulate the proliferation } \\
\text { and differentiation of the } \\
\text { former and greater vitality in } \\
\text { the latter }\end{array}$ \\
\hline $\begin{array}{l}\text { IL } 6 \\
1.6 \mathrm{ng} / \mathrm{L}\end{array}$ & & $\begin{array}{l}\text { Has pro-inflammatory properties and is } \\
\text { present in the acute phase of infection }\end{array}$ & & & \\
\hline $\begin{array}{l}\text { IL } 10 \\
0.13 \mathrm{ng} / \mathrm{L}\end{array}$ & & $\begin{array}{l}\text { Inhibit the activity of Th1 effector cells, NK } \\
\text { cells and macrophages and the production of } \\
\text { several pro inflammatory cytokines (IL-1, IL-6, } \\
\text { IL-8, and TNF- } \alpha \text { ) }\end{array}$ & $\begin{array}{l}\text { Provide immunoregulation } \\
\text { Attenue the immune response } \\
\text { Promote immunoglobulin synthesis }\end{array}$ & & \\
\hline $\begin{array}{l}\text { TGF } \beta \\
1.5 \mathrm{mg} / \mathrm{ml}\end{array}$ & & $\begin{array}{l}\text { Decreas pro-inflammatory cytokine } \\
\text { expression. }\end{array}$ & $\begin{array}{l}\text { Inhibits naïv T cells from differentiation into } \\
\text { Th1 and Th2 subtypes } \\
\text { Stimulates intestinal defense by switching } \\
\text { immunoglobulin classes from IgM to IgA in } \\
\text { B lymphocytes }\end{array}$ & & $\begin{array}{l}\text { Assistance with intestinal } \\
\text { mucosal repair }\end{array}$ \\
\hline $\begin{array}{l}\text { TNF } \alpha \\
620 \pm 183 \mathrm{pg} / \mathrm{mL}\end{array}$ & & $\begin{array}{l}\text { In association with its soluble receptor riduce } \\
\text { its pro-inflammatory activity }\end{array}$ & & & \\
\hline $\begin{array}{l}\text { EGF } \\
200 \mu \mathrm{g} / \mathrm{l} \text { in colostrum } \\
30-50 \mu \mathrm{g} / \mathrm{l} \text { in mature milk }\end{array}$ & & $\begin{array}{l}\text { Upregulation of IL } 10 \\
\text { Decrease livel of IL18 and mRNA IL18 }\end{array}$ & & & $\begin{array}{l}\text { Promote growth and } \\
\text { maturation of the fetal } \\
\text { pulmonary epithelium } \\
\text { Stimulates synthesis of DNA } \\
\text { in the digestive tract } \\
\text { Acelerates wound healing } \\
\text { Role in repair of the intestine } \\
\text { during intestinal injury } \\
\text { or infection }\end{array}$ \\
\hline $\begin{array}{l}\text { HB-EGF } \\
\text { concentrations } 2 \text { to } 3 \text { times } \\
\text { lower than EGF }\end{array}$ & Bind to pathogen & $\begin{array}{l}\text { Decrease pro-inflammatory citokine } \\
\text { expression }\end{array}$ & & & \\
\hline
\end{tabular}




VEGF
$74.3 \pm 34.9 \mathrm{ng} / \mathrm{ml}$ on the firs
day
$6.2 \pm 2.3 \mathrm{ng} / \mathrm{ml}$ on the fifth
day
$4 \mathrm{ng} / \mathrm{ml}$ in mature milk.
Chemochine
G-CSF
MIF
Adipokins

Lipids

omega-3 PUFAs

Inactivate pathogens

Omega-3 + omega-6

PUFAs

Free fatty acids (FFAs) and

monoglycerides

EPA

Oxysterols

nhibit the viral replication

\section{Antinflammatory}

Riduce TNF $\alpha$ and IL-6 levels

ytic effect on several viruses

Lactobacillus and Bifidobacterium species
Antagonize the pro-inflammatory effect of AA

Influence polarization of macrophages to anti-inflammatory phenotype

Inhibit expression of adhesion molecules Downregulate proinflammator gene Decrease

NF-kB, bind to PPAR- $\gamma$

$$
\text { migration }
$$

Casein and lactoalbumin

in the adherence to human respi-

ratory tract epithelial cells

Prevents the attachment to the

mucosal acting as a receptor analog

Inhibit the proteases of viruses

Secretory IgA

$12 \mathrm{mg} / \mathrm{ml}$ in colostrum

$1 \mathrm{mg} / \mathrm{ml}$ in mature milk

$\lg \mathrm{M}$

2-7 mg/100 ml

$\lg G$

$1-3 \mathrm{mg} / 100 \mathrm{ml}$

Lysozyme

$3-110 \mathrm{mg} / 100 \mathrm{ml}$
Bind to pathogens

Inhibition of pathogen attachment to

mucosal surfaces

to pathogenic microbes and antigens

Influence intestinal microbiome

Prevention of typical inflammatory response

avidity lgM antibodies reactive with viruses

bind, opsonization

and agglutination of pathogens

Inactivate, destroy or block the attack Eliminate trigger for acute inflammator

of specific microbes on the surfaces response

of the mucous membranes
Involved in the innate immune response against viruses

Factor inhibitory macrophage migration

Stimulate $t$ cell

ocyte response

nhibits T-cell response (modification of lipid Antithrombotic s and caveolae structure of membrane) Decrease degree of inflammator esponse-change membrane PL

concentration

(n)

of fibrinogen

aggregation by

changing the pair of the damage

Stimulate angiogenesis

Prevent intestinal edema

Intestinal

trophic factor

Role in fluid homeostasis

and regulation of

cardiovascular system

Angiogenesis

Affect cell growth and

apoptosis

Maintaining membrane

integrity

thrombin production

-less time of clot

Neurotrophic effect

Stimulus to the production

of neurons by stem cells

minor alterations

-reducing platelet

composition of platelet

membrane

phosfoptides

Alpha-lactalbumin induces apoptosis-like death with oeic acid

Inhibition of hydroxyl radical formation 


\begin{tabular}{|c|c|c|c|c|c|}
\hline & Antiviral & Antinflammatory & Immunomodulation & Anticoagulant & Repair of the damage \\
\hline $\begin{array}{l}\text { Lattoferrin (lactoferricin) } \\
0,5 \mathrm{gr} / \mathrm{dl} \text { in colostrum, } \\
0.2 \mathrm{gr} / \mathrm{dl} \text { at } 1 \text { month, } \\
0.1 \mathrm{gr} / \mathrm{dl} \text { later }\end{array}$ & $\begin{array}{l}\text { Iron sequestration } \\
\text { Act as natural barrier of both } \\
\text { respiratory and intestinal mucosa } \\
\text { Revert the iron disorders related to } \\
\text { the viral colonization } \\
\text { LPS/lipothecoic acid interaction } \\
\text { Serin protease activity } \\
\text { Proteoglycans interaction and } \\
\text { inhibition of replication of virus } \\
\text { Cell wall breakdown }\end{array}$ & $\begin{array}{l}\text { Eliminate trigger for acute inflammatoy } \\
\text { response } \\
\text { Inibit IL-1, IL-6, TNF- } \alpha, \text { IL-8 } \\
\text { Promote growth of probiotics }\end{array}$ & $\begin{array}{l}\text { Decrease pro-inflammatory cytokine } \\
\text { expression } \\
\text { Block excessive DC activation upon } \\
\text { TLR-induced inflammation } \\
\text { Regulate intestinal microbiome } \\
\text { Regulate innate and acquired immunity } \\
\text { Enhancing the activation of immune cells }\end{array}$ & Anti-fibrinolytic property & $\begin{array}{l}\text { Cell proliferation Maturation } \\
\text { of gut enzymes }\end{array}$ \\
\hline $\begin{array}{l}\text { Lacthoaderin } \\
3-33 \mathrm{mg} / 100 \mathrm{ml}\end{array}$ & $\begin{array}{l}\text { Binds specifically virus } \\
\text { Inhibits virus replication }\end{array}$ & $\begin{array}{l}\text { Induces IL-10 and TGF-b release from } \\
\text { regulatory T cells } \\
\text { Enhances the ability of macrophages to } \\
\text { phagocytize apoptotic cells } \\
\text { Blocks NK-kB pathway via TRL4 inhibition }\end{array}$ & $\begin{array}{l}\text { Prevent pro-inflammatory signaling and } \\
\text { decrease inflammatory response } \\
\text { Attenuate sepsis-induced apoptosis }\end{array}$ & $\begin{array}{l}\text { Function as an } \\
\text { anticoagulant and } \\
\text { regulate haemostasis } \\
\text { via homology of the } \mathrm{C} 2 \\
\text { domain to coagulation } \\
\text { factors VIII and } \mathrm{V} \text { and } \\
\text { the competition } \\
\text { between them for PL } \\
\text { membrane- } \\
\text { binding sites }\end{array}$ & $\begin{array}{l}\text { Inhibits excessive } \\
\text { neutrophils infiltrating to } \\
\text { organs } \\
\text { Moderate attenuation of } \\
\text { organ injury } \\
\text { Improves the } \\
\text { histopathology, the integrity } \\
\text { of the lung tissue and } \\
\text { decreases lung apoptosis } \\
\text { Reduction of renal tissue } \\
\text { histological damage } \\
\text { Promotion of mucosal } \\
\text { wound healing } \\
\text { Attenuation of intestinal } \\
\text { inflammation } \\
\text { Facilitate neoangiogenesis }\end{array}$ \\
\hline B defensin & Antimicrobial activity & Inhibit TLR7 & $\begin{array}{l}\text { Enhances TLR4/CD44-dependent intestinal } \\
\text { epithelial defense }\end{array}$ & & $\begin{array}{l}\text { Decrease in the long-term } \\
\text { risk of gastrointestinal } \\
\text { inflammatory diseases }\end{array}$ \\
\hline TLRs & & $\begin{array}{l}\text { Depress TLR signaling } \\
\text { Decoy receptor to inhibit IL-8, TNF }\end{array}$ & $\begin{array}{l}\text { Prevent pro-inflammatory cytokine } \\
\text { expression and inflammation }\end{array}$ & & \\
\hline Chondroitin sulfate & Antiviral agent & $\begin{array}{l}\text { Decrease production of proinflammatory } \\
\text { cytokines } \\
\text { Stimulate specific antioxidant enzymes }\end{array}$ & $\begin{array}{l}\text { Inhibit activity of nuclear-factor } \\
\text { kappalight-chain enhancer of activated B } \\
\text { cells } \\
\text { Promote the proliferation of anti- inflammatory } \\
\text { IL-10-secreting T-regulatory cells }\end{array}$ & $\begin{array}{l}\text { Has functions in } \\
\text { coagulation }\end{array}$ & Enhance wound healing \\
\hline Antioxidants & & Scavange free radicals & Prevent inflammation & & Prevent injury \\
\hline $\begin{array}{l}\text { Anti-proteasis } \\
(\alpha-1 \text {-antitrypsin, } \\
\alpha-1 \text {-antichymotrypsin, } \\
\text { elastase inhibitor }) \\
\alpha 1 \text {-Antitrypsin } \\
2-5 \mathrm{mg} / 100 \mathrm{ml}\end{array}$ & & $\begin{array}{l}\text { Metabolize protease produced by } \\
\text { inflammatory cells }\end{array}$ & Prevent excessive inflammatory response & & \\
\hline $\begin{array}{l}\text { MicroRNA } \\
47,240 \mu \mathrm{g} / \mathrm{L}\end{array}$ & & $\begin{array}{l}\text { Release of inflammatory mediators } \\
\text { Proliferation of neutrophils and monocytes }\end{array}$ & $\begin{array}{l}\text { Regulation of T- and B-cell development } \\
\text { Regulation of function of dendritic cells } \\
\text { and macrophages }\end{array}$ & & $\begin{array}{l}\text { Epigenetic regulation of } \\
\text { stem cells fate and function }\end{array}$ \\
\hline
\end{tabular}




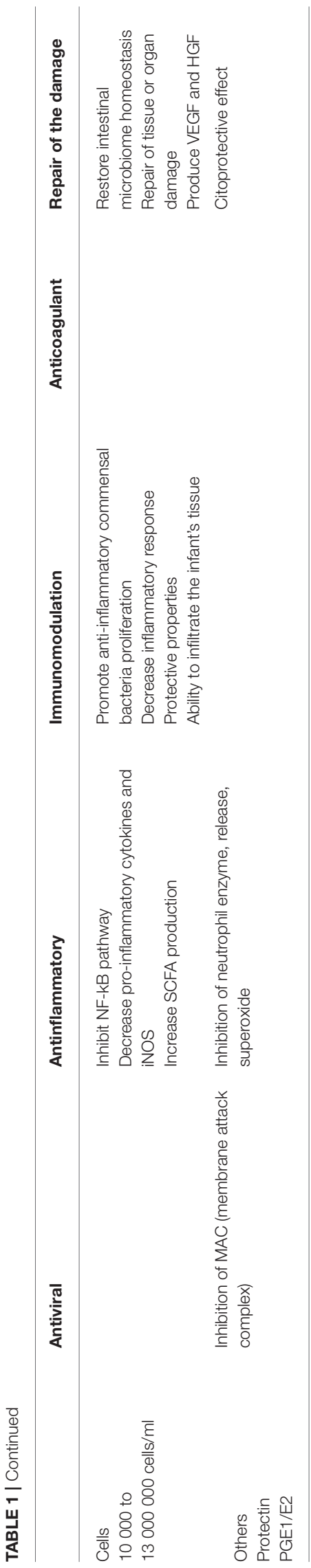

The intake of immunomodulatory constituents of human milk confers protection against the incidence and severity of gastrointestinal and respiratory diseases, providing passive protection through innate and adaptive mother's immunity (5). It is known that breastfed infants are more protected compared with formula-fed infants (6). The human milk carries immunoglobulins, lactoferrin (LF), and oligosaccharides that provide passive protection and other mediators like pro- and anti-inflammatory factors [tumor necrosis factor- $\alpha$ (TNF- $\alpha$ ), interleukin 1 (IL-1), prostaglandins E2 (PGE2), IL10 , transforming growth factor $\beta$ (TGF- $\beta$ ), Thromboxane A2 (TXA2), Ribonucleid Acid Messenger RNA (mRNA)], mediators of leukocyte differentiation, and antibodies. The human milk lymphocyte pattern includes activated $\mathrm{T}$ cells and memory $\mathrm{T}$ cells more activated than lymphocyte pattern in peripheral blood (7). In addition, antibodiescarried by human milk protect infants against microorganisms; the prevalent antibodies are Secretory Immunoglobuline A (SIgA) produced by plasma cells in mammary glands that can neutralize microbial toxin bacteria and virus. Similarly, SIgM is important against enteric antigens $(8,9)$.

\section{Human Milk Oligosaccharides}

Human milk oligosaccharides (HMOs) are a group of structurally unconjugated glycans, carbohydrates with a highly complex structure, from three to 10 monosaccharides, and differ in the degree of polymerization, carbohydrate content, type of glycosidic bonds, and ramifications (10). They are highly abundant and unique in human milk and represent the third largest solid component after lactose and lipids (11) (from 5 to $12 \mathrm{~g} / \mathrm{L}$ in mature milk to $>20 \mathrm{~g} / \mathrm{L}$ in colostrum). More than 200 isomers and 162 chemical structures are known $(10,12$, 13). HMOs are classified into three groups: neutral fucosylated (including 20-fucosyllactose, 20-FL), neutral non-fucosylated [including lacto-N-neotetraose (LNnT)], and acidic [including 30-sialyllactose (30-SL) and 60-sialyllactose (60-SL)] (14-16). Fucosylated HMOs are the most conspicuous component (77\%), while sialylated HMOs represent $16 \%$. HMOs are not a primary energy source for the child but perform important biological functions: enhance gut maturation; act as prebiotics, antiadhesives, and antimicrobials; and directly modulate immune responses; thus, they may play an important role in the protective health effects of breast milk $(17,18)$. They are not digested, and they reach the systemic circulation intact $(19,20)$ so they may exert their functions.

HMO structure depends on two specific genes, and each lactating mother synthesizes a unique subset, influenced by genetics and enzymes that process HMOs $(21,22)$. Furthermore, in terms of quantity and structure, HMOs vary from woman to woman and in the same woman during breastfeeding (23).

\section{Functions of Human Milk Oligosaccharides Interaction With Pathogens}

HMOs are potent antimicrobial factors in human milk (Figure 1). Viral, bacterial, or protozoan pathogens need to adhere to mucosal surfaces to colonize or invade the host and cause disease. HMOs reduce infections by serving as antiadhesive antimicrobials $(25,26)$, inhibiting the adhesion of 


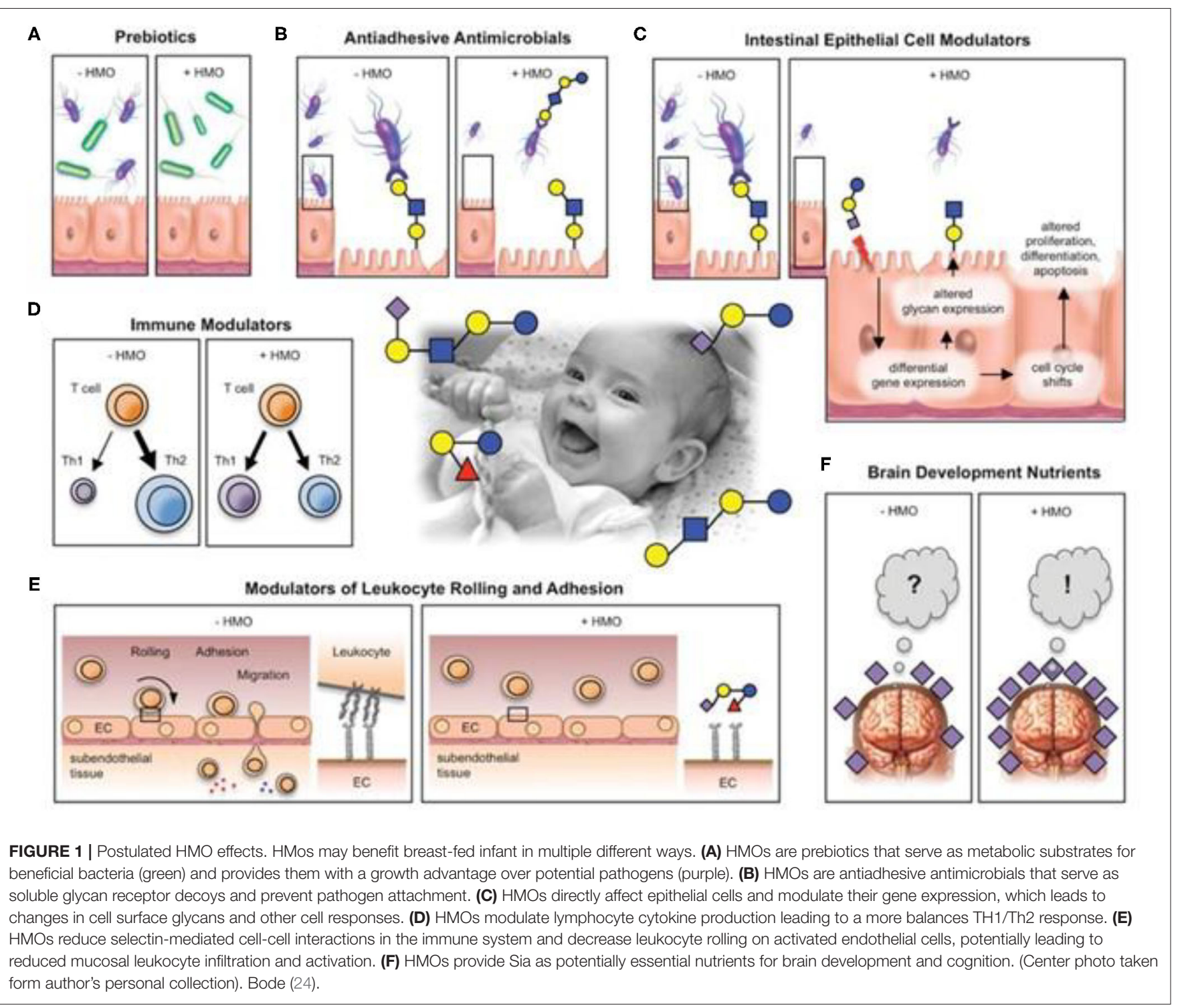

pathogens to the surface of the host cells. Many HMOs act as a soluble analog of pathogen receptors, they have a structure very similar to cell surface receptors (glycocalyx) (anti-adhesion property), and they modify the expression of glycocalyx gene (modifying property) $(11,17)$. This mechanism modulates the expression of immune signaling genes, which have been shown to repress inflammation of the mucosal surface $(27,28)$. So, anti-adhesive activity and probiotic activity secondarily reduce inflammation within the intestine (29). HMOs and glycans also inhibit infection acidifying the gut lumen (28); they produce bacteriocins and organic acids that prevent pathogen growth (30).

Sialylated oligosaccharides can act as inhibitors against the enterotoxins produced by Vibrio cholerae and Escherichia coli. In mice infected with adherent-invasive E. coli (AIEC), 20-FL was effective in reducing pathogen colonization, modulating AIECinduced CD14 expression and attenuating inflammation (31).
Physiological concentrations of HMOs have been able to inhibit the adhesion of Entamoeba histolytica, responsible for a widespread parasitic disease characterized by high mortality, to the layers of enteric epithelial cells and its cytotoxicity in a dose-dependent manner. The main adhesion-related virulence factor in E. histolytica is a lectin that binds with galactose and $\mathrm{N}$-acetyl-galactosamine; HMOs contain terminal galactose, such as lacto-N-tetraose (LNT), that acts as decoy receptors. Glycanmediated attachment mechanisms have also been described for many viruses like noroviruses or rotaviruses (32) and bacterial infection too. 2-FL is one of the most prominent short-chain oligosaccharides, and it is associated with the antiinfective capacity of human milk. During Campylobacter jejuni infection, 2-FL reduces colonization and moderates intestinal inflammation; so, the use of 2-FL as an oral agent for the prevention and treatment of this infection is being studied (33). At that place are numerous works that have assessed the clinical 
use of HMOs. For example, venous injection into the tail of mice of analogs of HMOs (Gal-1-4Gal-1-4Glc) demonstrated its rapid diffusion and the effect of reducing urinary infections by 10 times (34).

\section{Probiotic Effect}

HMOs are natural prebiotics that are resistant to digestion during their passage through the small intestine; infants lack glycolytic enzymes needed to break them down, and they reach the large intestine, where they are a selective substrate for bifidobacteria (35-37). These bacteria digest HMOs producing short-chain fatty acids (SCFAs), an energy source for the epithelial cells of the colon with a positive trophic effect on the intestinal cells. They produce an acidic milieu in the gut, making it inhospitable to potentially pathogenic microbes (37, 38 ); moreover, they modulate the immune system and promote the gut epithelial barrier function (22), establishing a stable ecosystem in an infant's gut. It is now recognized that a healthy microbiota has a positive impact on human health and provides benefits that go far beyond effects in the gastrointestinal tract. For instance, impairment of the gastrointestinal microbiota is associated with chronic activation of the immune system and human immunodeficiency virus (HIV) disease progression (39). In respiratory viral infections, the microbiome composition stimulates production of virus-specific CD4+ and CD8+ $\mathrm{T}$ lymphocytes and virus-specific antibodies (32).

The SCFA produced by the fermentation of HMOs have also well-established anti-inflammatory properties (40). Data from animal models strongly suggest a protective role for SCFAs; the SCFA receptor GPR43 was found in asthma, arthritis, and colitis models and GPR41 in allergic airway inflammation (41-45).

\section{Immunomodulatory Effect}

HMOs also directly modulate immune responses. Data from literature documented that SCFAs are involved in immune response regulation function; indeed, they promote the development and influence the function of regulatory $\mathrm{T}$ cells (Tregs), an action that limits intestinal inflammation and regulate gene expression, with consequent inhibition of interferon (IFN) production and the suppression of activation of the nuclear factor kappa Beta (NF- $\kappa \mathrm{B})$ in the epithelial cells of the human colon (46). This mechanism is responsible for the first immune inflammatory responses, and its dysregulation is found in inflammatory bowel diseases (47). HMOs may act locally on cells of the lymphoid tissues or through the systemic circulation $(48,49)$, where it interacts with selectins, dendritic cells (DCs), integrins, and Toll-like receptors (TLRs). Selectins are glycoproteins involved in the immune response in the initiating signal of the inflammatory cascade. HMOs induce structural modifications of selectins, reducing the immune response as adhesion, migration, leukocyte activation in vitro. In particular, the sialylated HMOs inhibit the adhesion, mediated by lecitins, of leukocytes to the endothelium; they limit the recruitment from the blood and suppress the infiltration of leukocytes (50); in this way, they modulate the escalation of the immune response (1).
Colostrum HMOs have been shown to modulate immune signaling pathways, including TLR3, TLR5, and IL-1-dependent pathogen-associated molecular pathways (PAMPs), and subsequently to decrease acute-phase inflammatory cytokine secretion. For example, 3'-galactosyllactose directly inhibits polyinosine-polycytidylic acid, which, in turn, decreases levels of the potent pro-inflammatory cytokine, IL-8 (27).

Studies demonstrate that the injection of milk-N-fucopentose III or milk-N-neotetraose oligosaccharide into mice caused the proliferation of a subpopulation of peritoneal macrophages that suppress CD4+ lymphocytes and the activation of natural killer (NK) cells (51) and, in the other way, the suppression of proliferation of naive CD4+ T lymphocytes through secretion of IL-10 and IL-13 by macrophages (52). Moreover, when cord blood $\mathrm{T}$ cells are exposed to sialylated HMOs, an increase in the number of IFN- $\gamma$-producing CD3+CD $4+$ and CD $3+C D 8+$ lymphocytes have been observed, as well as IL-13-producing CD3+CD8+ lymphocytes (53). Not only in vitro but also ex vivo, data suggest that HMOs can interfere with selectins that mediate the earliest stages of leukocyte trafficking and platelet-neutrophil complex (PNC) formation (54).

\section{Cytokines and Chemokines}

The newborn cytokine pool is lacking; instead, these mediators [IL-1b, IL-2, IL-6, IL-8, IL-10, IL-12, IL-18, IFN- $\gamma$, TNF$\alpha$, TGF-b, granulocyte colony-stimulating factor (G-CSF), macrophage colony-stimulating factor (M-CS), granulocytemacrophage colony-stimulating factor (GM-CSF)] abound in breast milk, which is the ideal source $(55,56)$, and can make up for this deficiency. Accessibility of cytokines from breast milk is important to modulate the immediate and long-term inflammatory response of the infant.

Moreover, they may reach the intestine unaltered, thanks to the protease inhibitors (a1-antichymotrypsin and a1-antitrypsin) present in breast milk that preserve them from digestion. These cytokines are small proteins or peptides that act as intercellular messengers and elicit a particular response after binding to a receptor on a target cell. They represent an important biological component of maternal milk, thanks to their role in the function of immune regulation, hematopoiesis, and inflammation, and they may make up for the immaturity of the neonatal immune system and the consequent insufficient anti-inflammatory and anti-infective response. While many cytokines and chemokines have multiple functions, milk-borne cytokines may be grouped broadly into those that enhance inflammation or defend against infection and those that reduce inflammation (57).

There is large variability between cytokine concentrations among breastfeeding women, and pro-inflammatory ones are generally low. In addition, most milk $\mathrm{T}$ lymphocytes show the activation of CD45RO marker, in contrast to neonatal $\mathrm{T}$ lymphocytes, which mainly express the "naive" CD45RA phenotype. The production of cytokines in breast milk has been demonstrated by CD4+ and CD8+ T cells, which express the antigen CD45RA or CD45RO, and the percentage of cytokineproducing cells in breast milk is higher than that in cord blood (58). 
High levels of IL-1 and receptors have been detected in breast milk, as well as a significant function of this cytokine has been demonstrated both ex vivo and in vitro. IL-1 receptor antagonist (IL-1RA) limits inflammation competing with the pro-inflammatory cytokine (59). The possibility of having inflammatory and anti-inflammatory systems in a balance that depends on the conditions that call for it is an extremely intriguing feature of breast milk. One of the most important mechanisms underlying the protective effect of breast milk, for example, against necrotizing enterocolitis (NEC), is the ability to attenuate the inflammatory immune response mediated by NF- $\mathrm{KB}$ in enterocytes. This occurs through the reduction of the activity of IL-1, which induces the innate endogenous inflammatory response, upregulating the expression of proinflammatory IL- 8 and stimulating the pathway of the NF- $\kappa$ B $(60,61)$.

Breast milk, especially in colostrum and less in the mature one, is rich in IL-2 that intervenes in the recruitment of T cells necessary to produce an antigen-specific immune response, supporting in this function the newborn who, on the other hand, is notoriously particularly lacking in it. The high percentages of Th1-type cytokines (IL-2 and, particularly, IFN- $\gamma$ ) may play an important role in the differentiation of neonatal $\mathrm{T}$ cells in a preferential Th1, rather than Th2, pathway.

Breast milk IL-10, in maximum concentrations in the first $24 \mathrm{~h}$ of life, is a powerful anti-inflammatory; it is able to inhibit the activity of Th1 effector cells, NK cells, and macrophages and the production of several pro-inflammatory cytokines (IL-1, IL6, IL-8, and TNF- $\alpha$ ), thus attenuating the immune response (62). IL-10 increases the survival and expansion of B cells, inhibits Th1 responses, and downregulates major histocompatibility complexII expression on monocytes, thus, limiting their antigenpresenting cell function. IL-10 has been heavily implicated in the regulation of intestinal inflammation and regulating responses to the microbiome (56).

Two effective pro-inflammatory cytokines, IFN- $\gamma$ and TNF$\alpha$, are missing in the newborn. IFN- $\gamma$, secreted by activated $\mathrm{T}$ cells and NK cells even if at low concentrations, is involved in signaling pathways that increase intestinal epithelial barrier permeability and improves the activation of intestinal macrophages; it is also detected in higher concentrations in the ileum of patients with NEC $(63,64)$. TNF- $\alpha$ is an endogenous pyrogen; it contributes to systemic inflammation and performs a regulatory immune cell function (62).

Colostrum contains high amounts of IL-8, which is significantly reduced in the later stages of breastfeeding, an interleukin that protects the newborn from sepsis and NEC. The exposure of intestinal cells intact or with injury to the recombinant IL-8 in vitro has stimulated the proliferation and differentiation of the former and greater vitality in the latter, suggesting an important role in the physiological development of the intestine (65).

Human milk contains physiologically relevant concentrations (up to $1.5 \mathrm{mg} / \mathrm{ml}$ ) of TGF- $\beta$, a multifunctional secretory cytokine expressed by most cell types, parenchymal cells, and infiltrating cells, such as lymphocytes, macrophages, and platelets (66). TGF- $\beta_{1}$ is the predominant TGF- $\beta$ isoform produced by immune cells, whereas TGF- $\beta_{2}$ is most abundant in secretions including breast milk. The main activities of TGF$\beta$ are immune modulation, regulating the cellular proliferation and differentiation and decreasing pro-inflammatory cytokine expression. In particular, TGF- $\beta$ immunomodulatory properties including intestinal maturation and defense, by switching immunoglobulin classes from IgM to IgA in B lymphocytes, immunoglobulin production in the mammary gland and gastrointestinal tract of the newborn, assistance with intestinal mucosal repair (67), and induction of oral tolerance (68). TGF$\beta$ also helps stabilize forkhead box P3 (FOXP3) expression and maintains the differentiation of Tregs, which inhibit immune responses and inflammation (69).

In several clinical studies, higher concentrations of TGF- $\beta$ in milk are associated with the reduction of the incidence of neonatal diseases, in particular, respiratory and allergies, and a positive correlation between TGF- $\beta$ levels and the neonatal production of immunoglobulins $(70,71)$. It has also been reported to inhibit inflammation in the intestinal epithelium and systemic production of IL- 6 and IFN- $\gamma$, reducing the incidence of NEC $(72,73)$. In contrast, developmental defects rather than immunological dysregulation were observed in TGF- $\beta 2$-deficient mice (74).

An abundant peptide in breast milk is the epidermal growth factor (EGF), which acts on the intestine by improving the barrier functions and nutrient transport and enhancing enzyme activity (75). The roles of EGF in the development of the intestine, as well as the response and repair of the intestine during intestinal injury or infection, have been reported (76). Inflammatory diseases of the small intestine are associated with an IL-18 dysregulation condition, and experimental NEC rats, treated with EGF, showed a decrease in the levels of pro-inflammatory cytokines, IL-18, on the intestinal damage site, as well as IL-18 mRNA levels. But the anti-inflammatory effect of EGF is also expressed through the upregulation of IL-10 $(75,77)$. EGF promotes the growth and maturation of the fetal pulmonary epithelium, stimulates the activity of ornithine decarboxylase and the synthesis of DNA in the digestive tract, and accelerates wound healing (78). EGF is highest in early milk and decreases over lactation. The average EGF level in colostrum is 2,000-fold higher and in mature milk is 100 -fold higher than in maternal serum. Further, preterm milk contains higher levels of EGF than term milk (79).

Heparin-binding EGF-like growth factor (HB-EGF), a member of the EGF family of growth factors, also protects against intestinal injury in the developing intestine by binding to pathogenic bacteria (80). Rats that underwent ischemic/reperfusion injury had less pro-inflammatory cytokine expression, particularly TNF- $\alpha$ and IL-6, ex vivo (81). HB-EGF is expressed in response to hypoxia, tissue damage, and oxidative stress, including in the intestine, and has a pivotal role in tissue regeneration and repair (82).

Similarly, vascular endothelial growth factor (VEGF) is a glycoprotein present in breast milk, at higher levels in the colostrum and breast milk of mothers with preterm infants than those with term infants (83). Its primary role is mediating angiogenesis, but it has been suggested that VEGF may also have anti-inflammatory effects. In a study performed by Karatepe et al. 
(84), rats induced with NEC and given subcutaneous VEGF had less villous atrophy and less intestinal edema, as well as lower TNF- $\alpha$ and IL- 6 levels when compared to NEC-induced rats that were not treated with VEGF.

CXC chemokines, powerful neutrophil activators, are present in large quantities in breast milk and perform chemotactic activities for intraepithelial lymphocytes and play an important role in the defense of the host against bacterial and viral infections (85).

\section{Lipids}

Lipid fractions in human milk include $34-47 \%$ of saturated fatty acids (SFAs) with principally $17-25 \%$ palmitic acid, $31-43 \%$ monounsaturated fatty acids (MUFAs), $12-26 \%$ n-6 polyunsaturated fatty acids (PUFAs), 0.8-3.6\% n-3 PUFA (22). Breast milk contains a high proportion of omega-3. PUFAs are involved in regulating immune and inflammatory responses by inhibiting the induction of inflammatory genes binding to the nuclear receptor, peroxisome proliferator-activated receptor (PPAR) (86). Moreover, omega-3 PUFA decreases the activity of NF- $\kappa \mathrm{B}$ that induces a range of pro-inflammatory genes, including cyclooxygenase 2 (COX-2), intercellular adhesion molecule-1 (ICAM-1), vascular cell adhesion molecule-1, E-selectin, TNF- $\alpha$, IL-1B, inducible nitric oxide synthase, and acute-phase proteins. PUFA in human milk can modulate immunological responses, affecting the balance between Th1 and Th2 cells and Treg and T helper cells from the acquired immune response (87). Omega3 PUFAs change the membrane phospholipid composition by increasing arachidonic acid, subsequently decreasing the systemic inflammatory response syndrome; they also inhibit migration of leukocytes to infection sites (88). Supplementation of a combination of omega- 3 and omega- 6 PUFAs decreased the incidence of NEC and intestinal inflammation via decreased platelet-activating factor (PAF)-induced TLR4 activation in mice $(89,90)$. In addition, specialized pro-resolving mediators (SPMs), derived from omega-3 PUFA, specifically resolve inflammation by stopping polymorphonuclear cell migration and protect against chronic inflammatory conditions, including colitis, neuroinflammation, and arthritis (91). Omega-3 PUFAs also increase anti-inflammatory microbes, such as Lactobacillus and Bifidobacterium species $(92,93)$. The long-chain PUFA (LCPUFA), Docosahexaenoic Acid (DHA), and Amino Acids (AAs) are essentials as immunomodulators also by production and regulation of inflammatory cytokines, leukotrienes, prostaglandins, and thromboxanes (94).

Phospholipids contribute 1-2\% of the total lipids of human milk. The major phospholipids of milk fat globule membrane are phosphatidylcholines, phosphatidylethanolamines, and sphingomyelins, and each of it contributes $20-40 \%$ of the total phospholipids $(95,96)$. The sphingomyelin demonstrates robust antitumor activity, may influence cholesterol metabolism, and exhibits anti-infective activity (97). Breast milk lipids have been demonstrated to inactivate a number of pathogens in vitro, including Group B streptococcus (GBS), and provide additional protection from invasive infections at the mucosal surface, especially medium-chain monoglycerides $(98,99)$. Free fatty acids (FFAs) and monoglycerides, the digestive products of triglycerides, have a lytic effect on several viruses and also have an antiprotozoal action, particularly against Giardia (99). FFAs destroy the viral lipid envelope and express an important antiviral activity against the enveloped virus, including hepatitis C virus (HCV) and HIV $(100,101)$.

Oxysterols are cholesterol oxidation derivatives, and they were present in breast milk in all stages of lactation; they are characterized by a broad antiviral activity, and they are involved in the innate immune response against viruses. They inhibit the viral replication, and their antiviral power has been observed against a number of enveloped viruses but also in relation to several non-enveloped viruses. They were active in vitro against the human rotavirus and the human rhinovirus, two relevant pediatric viral pathogens $(102,103)$.

\section{Proteins}

One of the special features of breast milk proteins is that they are present in an inversely proportional way to the production capacity of the baby, and they are able to gradually decrease over time as the baby's defenses increase or increase in case of need. Breast milk contains several hundred proteins, which play functional roles in the protection of the child; they provide nutrition, stimulate the absorption of nutrients, and provide biological activities, ranging from antimicrobial effects to immunostimulatory. These molecules have broad-spectrum anti-infective power against bacteria, viruses, and fungi, as well as synergic activity with conventional antibiotics $(104,105)$.

The composition of human milk proteins makes them $100 \%$ assimilable by the infant's body, and they are divided into three groups: caseins, whey proteins, and those linked with the membrane of the milk fat globule. Whey protein is the main colostrum protein; while in mature milk, it is equivalent to $60 \%$. Proteins, such as $\beta$-casein, perform important antiseptic and anti-infectious functions inhibiting the proteases of bacteria and viruses. Furthermore, the peptides produced by the digestion of $\alpha$-lactalbumin show a potent antibacterial action against Gram-positive and Gram-negative bacteria. Other human milk proteins, such as SIgA, LF, and lysozyme, act as essentially antiinfectious agents for premature babies carrying out a synergistic action to inactivate, destroy, or block the attack of specific microbes on the surfaces of the mucous membranes (106). Lipoproteins can cause cell lysis in influenza virus infection (107).

SIgA provides immunological protection to the infant, while its own immune system matures (108). The concentration in colostrum is about $12 \mathrm{mg} / \mathrm{ml}$; mature milk contains $1 \mathrm{mg} / \mathrm{ml}$.

SIgA antibodies in breast milk are essential in the defense of the mucous membranes: prevent the entry of microorganisms in the tissues; they are anti-inflammatory and do not consume energy during the reaction $(109,110)$. Interestingly, $74 \%$ of bacteria in the gut lumen are coated with SIgA (111). Given this role, it is not surprising that SIgA influences the composition of the intestinal microbiome and, furthermore, promotes intestinal homeostasis by preventing inappropriate inflammatory responses to pathogenic microbes and nutritional antigens. In a recent study by Gopalakrishna et al. (112), maternal milk-fed infants had higher percentages of SIgA that were bound to bacteria compared to formula-fed infants. In 
addition, higher percentages of SIgA bound to bacteria in the intestine of preterm infants were associated with lower rates of NEC. Furthermore, it was observed that lower levels of SIgA-bound bacteria were inversely associated with abundance of enterobacteria among infants who developed NEC. Thus, SIgA binding to bacteria presumably plays a protective role against NEC, likely by limiting inflammation induced by Enterobacteriaceae (27). Specifically, SIgA molecules remain active throughout the newborn's gastrointestinal tract and impact the binding of commensal or pathogenic microorganisms, toxins, viruses, and other antigenic materials, such as lipopolysaccharide (LPS), preventing their adherence and penetration into the epithelium without triggering inflammatory responses that could be harmful to the newborn, a mechanism known as immune exclusion. High-affinity IgA and IgM antibodies transported by the polymeric immunoglobulin receptor ( $\mathrm{PIgR}$ ) may even inactivate viruses (e.g., rotavirus and influenza virus) within epithelial cells and carry these pathogens and their products back into the lumen, thereby avoiding cytolytic damage to the epithelium (113). Breast milk contains antibodies protective against V. cholerae, Campylobacter, Shigella, Giardia lamblia, and respiratory tract infections (114); adherence of S. pneumoniae and Haemophilus influenza to human retropharyngeal cells is blocked by SIgA antibody in breast milk $(114,115)$. IgM and IgG are less in human milk, but they have known immunesurveillance properties. High-avidity IgM antibodies may act as an important part in protecting the mucosal surfaces of infants against viruses and bacteria. IgG plays an anti-inflammatory role by direct binding, opsonization, and agglutination of pathogens $(79,114,115)$. IgG is mainly transferred via the placenta from mother to fetus, but they are also produced in the mammary gland and detected in a majority of colostrum samples of mothers, adding to the much-needed immunological protection to the vulnerable infant.

\section{Lactoferrin}

LF is the dominant whey protein in human milk $(0.5 \mathrm{~g} / \mathrm{dl}$ in colostrum, $0.2 \mathrm{~g} / \mathrm{dl}$ at $1 \mathrm{month}, 0.1 \mathrm{~g} / \mathrm{dl}$ later) and has been demonstrated to perform a wide array of functions, protecting the newborn infant from infection and contributing to the maturation of the newborn innate and adaptive immune systems. More precisely, LF is the second most abundant protein in breast milk, and its biological functions range from antimicrobial activities against a large panel of microorganisms, including bacteria, viruses, fungi, and parasites, to regulation of cellular proliferation and differentiation, as well as anti-inflammatory, immunomodulatory, and anticancer activities (116).

LF has a high rate of survival after oral administration. In the stomach, pepsin digests and releases a potent peptide antibiotic called lactoferricin from native LF. Among all of the bioactive substances found in human milk, LF may be the one most comprehensively involved in milk's well-known anti-infective actions. A robust background of experimental research supports a leading use of LF in promoting the establishment of immune and defensive competencies in the neonate and young babies. In the last few years, solid evidence originating from a Randomized
Clinical Trial (RCT) has provided clinical confirmation of these properties. LF has been demonstrated to inhibit in vitro replication of human cytomegalovirus, $H I V$, herpesvirus, hepatitis $B$ and $C$ viruses, hantavirus, human papillomavirus, rotavirus, adenovirus, and influenza $A$ (117).

LF has a bacteriostatic function and cytotoxic effect against bacteria, viruses, and fungi and carries out immunomodulatory functions, helping to limit excessive immune reactions by blocking many inflammatory cytokines, such as IL-1 $\beta$, IL-6, TNF$\alpha$, and IL-8 $(118,119)$ while stimulating the natural process and maturation of the child's immune system (85).

In detail, N-terminal receptors for LF have been identified on the surfaces of many microorganisms. The binding of LF with these receptor sites is able to induce cell death in Gram-negative bacteria through a structural alteration of the bacterial LPS, with a consequent increase in permeability and greater susceptibility to lysosomal enzymes and antibacterial agents (120).

In E. coli infection, LF inhibits adherence and biofilm formation potentially by binding to the lipid portions of the LPS layer and through the degradation of virulence proteins anchored to the external membrane (121). In vitro LF is able to prevent the formation of the biofilm of Pseudomonas aeruginosa. In fact, in the absence of iron, this bacterium seems to have poor mobility, which results in the impossibility of surface adhesion (122). The proteolytic activity of LF is able to inhibit the bacterial growth of Shigella flexneri or enteropathogenic bacteria (5).

It has also been reevaluated for its antiviral capabilities, and some of them are expressed through the attachment of LF to surface proteoglycans, such as heparan sulfate, through its $\mathrm{N}$ terminus glycosaminoglycan-binding domains, thus blocking the entry of certain viruses into the cell, guaranteeing an arrest of the infection in its early stages $(5,123)$. In a study conducted in vitro on the activity of LF against the main pathogenic viruses (124), the results demonstrated LF inhibitory activity against a large variety of viruses. LF prevents DC-mediated HIV type 1 transmission by blocking the DC-SIGN-gp120 interaction (125) and human HCV infection, and a direct interaction between LF and E1 and E2 HCV envelope proteins has been proven (117).

LF can be considered a regulator of both innate and acquired immunity (126). The effects of LF on the innate immune response are related to its ability to bind to a variety of targets, first of all PAMP, present on pathogens (e.g., LPS on Gram-negative bacteria and peptidoglycans on Gram-positive bacteria), and thereby it competes with LBP, inhibiting the release of proinflammatory cytokines $(118,122,127)$. Data indicate that the interference of LF in the LPS-CD14 interaction may inhibit the expression of E-selectin, ICAM-1, and IL-8 by human umbilical vein endothelial cells, showing that the LF may also modulate the recruitment of immune cells by interfering with the expression of endothelial cell adhesion molecule, required for the recruitment of these cells to sites of inflammation $(118,127)$. $\mathrm{LF}$ is also capable of enhancing the activation of immune cells. Following bacterial invasion, LPS binds to TLR4 on sentinel cells to cause the release of potent cytokines, including TNF$\alpha$, IL-1, and IL-6 $(127,128)$. These molecules will activate and modify the permeability of endothelial cells to allow the passage of complements and antibodies and recruit neutrophils to the 
site of inflammation. Activated neutrophils will release LF from their secondary granules to exert its direct microbicidal effects (127). LF may also enhance the cytotoxic functions of NK and lymphokine-activated killer cells, potentially through binding to RNA and DNA. On macrophages, there are LF receptors, and the LF binding activates macrophages to release pro-inflammatory molecules, e.g., TNF- $\alpha$, IL-8, and nitric oxide (129), and increases their phagocytic activity when infected (130). For example, it increases phagocytic killing of Staphylococcus aureus (131).

LF plays an important immunomodulatory role in activation and antigen presentation by antigen-presenting cells (APCs), modulation of $\mathrm{T}$ cell development $(132,133)$, and maturation of DCs, enhancing IL-8 and CXCL10 release, decreasing antigen internalization, and increasing their capacity to trigger proliferation and release IFN- $\alpha$ (134).

When administered orally, LF has the ability to restore the host $\mathrm{T}$ cell compartment by an increase in splenic cellularity and enrichment of CD3 + CD4 + T lymphocytes, suggesting a possible function for $\mathrm{LF}$ in the reconstitution of the cellular immune response (135).

During the last years, literature data confirmed the crucial role of LF in the development of the intestinal microbiome, an important finding for hospitalized term and preterm infants at risk of invasive infection and NEC (136). It was shown that the integration of $100 \mathrm{mg} /$ day of LF in preterm births reduces the onset of delayed sepsis and intestinal necrosis $(127,137,138)$. LF also acts as a natural and specific inhibitor of the Urokinase Plasminogen Activator (uPA)-mediated plasminogen activation (139); high levels of LF were reported to be secreted by apoptotic cells (140). In apoptosis, LF might be necessary to downregulate the extracellular plasmin activity to avoid unwanted degradation of the surrounding tissue, inappropriate cell migration, or activation of proenzymes; the serum levels of LF might further increase during pregnancy. Thus, an anti-fibrinolytic property of LF may provide an intriguing clue to the reported higher risk of thromboembolism during pregnancy $(141,142)$. This view is especially relevant if we consider that thromboembolism is one of the most destructive mechanisms currently recognized in COVID-19 $(143,144)$. LF has been shown to act as a natural barrier of both respiratory and intestinal mucosa or reverting the iron disorders related to the viral colonization as an antiviral, anti-inflammatory, and immunomediator (145).

\section{Lactadherin}

Lactadherin has antimicrobial and antiviral effects and plays an important role in the immune defense. Lactadherin can be considered a multifunctional glycoprotein involved in the regulation of many biological and physiological processes, such as angiogenesis, atherosclerosis, hemostasis, phagocytosis, and tissue remodeling. The intrinsic endogenous activities of lactadherin include promotion of mucosal wound healing and attenuation of intestinal inflammation ex vivo and in vitro (146-148). Lactadherin also induces IL-10 and TGF- $\beta$ release from Tregs and promotes intestinal DC development (146). It enhances the ability of macrophages to phagocytize apoptotic cells, thereby ameliorating inflammatory processes induced by $\mathrm{NF}-\kappa \mathrm{B}$ and mitogen-activated protein kinase (149). It activates the signal transducer and activator of transcription 3-suppressor of cytokine signaling three pathways, directly quenching LPS induced TNF- $\alpha$ production $(146,147,149)$. Indeed, it has been reported that recombinant lactadherin may attenuate sepsisinduced apoptosis (150).

Milk lactadherin is present in the intestines of breastfed infant and could gain access to the circulation with its strong anticoagulant effects. It can mediate clearance of phosphatidylserine-expressing procoagulant platelet-derived microvesicles (151). Given the homology of its C2 domain to coagulation factors VIII and V and the competition between them for platelet membrane-binding sites, lactadherin could function as an anticoagulant and thereby regulate hemostasis. Many diseases induce strong procoagulation processes, including sepsis, suggesting other possible protective activities (152). Thus, orally ingested lactadherin could potentially be used for the prevention and treatment of intestinal injury in infants.

\section{Human $\beta$-Defensin}

Human milk contains small bioactive peptides, including defensins; of these, human $\beta$-defensin (HBD)-1 may act synergistically with other peptides present in breast milk. Also, HBD-1 acts as a chemotactic agent to recruit DCs, $\mathrm{T}$ cells to mucosal surfaces (respiratory, gastrointestinal, and nasopharynx), thus acting as a link between innate and adaptive immunity for the neonate (153). HBD-2 is present at 8.5 $\mathrm{mg} / \mathrm{ml}$ in colostrum and $1 \mathrm{mg} / \mathrm{ml}$ in mature milk, and it has antimicrobial activity against pathogenic bacteria (154). This suggests that the presence of HBD-2 in milk may help to defend both the mammary gland and the infant intestine. HBD-2 enhances TLR4/CD44 against intestinal pathogens (1). Low concentrations of HBD-2 are associated with lower TLR4lymphocyte antigen concentrations and more severe NEC (155). HBD-2 also suppresses TLR7 expression (54) that is stimulated by single-stranded RNA, and during a virus infection, it mediates signaling that leads to the release of IFN (156). HBD-2 in milk may contribute to decrease, in the long-term, the risk of gastrointestinal inflammatory diseases in the breastfed infant and to reduce the risk of breast cancer in mothers who had breastfed (157). Low levels of HBD-1 and HBD-2 in preterm infants are associated with increased incidence of intestinal pathology and onset of NEC. Animal models have shown that depletion of Paneth cells rich in defensins followed by enteric infection in test animals resulted in a clinical picture akin to human NEC (158). A synthetic analog of HBD (brilacidin) is tested in a phase II trial for the treatment of acute bacterial skin infections and in preclinical phase for otitis and ocular infections (159).

\section{Osteopontin}

It is a multifunctional glycosylated and heavily phosphorylated acidic protein. The average concentration in breast milk is comparatively high $(\sim 140 \mathrm{mg} / \mathrm{L})$ and about half maximal levels are maintained beyond 1 year of lactation (160). It also plays an important role in immune activation and immune regulation by acting as chemotactic agent and stimulates both pro- and anti-inflammatory processes. It enhances B lymphocyte immunoglobulin production and proliferation and 
also influences cell-mediated immunity by inducing Th1 cells (161). Furthermore, it also has been shown to form complexes with LF and act as a carrier for other immunomodulator proteins to enhance their competencies (162). Infants fed formula supplemented with osteopontin (OPN) had significantly low serum concentrations of the pro-inflammatory cytokines; the cytokine profile is more similar to that of breastfed infants and days of illness were significantly lower, and these data strongly suggest that OPN affects immune function in infants, conferring health benefits (163).

\section{Antiprotease and Antioxidant Factors}

Indeed, oxidative stress may be involved in serious diseases in premature infants, including NEC, chronic lung disease, and retinopathy of prematurity (ROP) (164). Human milk contains anti-proteases, including $\alpha$-1-antitrypsin, $\alpha$-1-antichymotrypsin, and elastase inhibitor, which limit the ability for pathogens to enter the body, thereby limiting inflammation locally (109). It also contains various antioxidative agents, including enzymes [catalase, glutathione peroxidase (GPx), and superoxide dismutase (SOD)], constituents of antioxidative enzymes (e.g., $\mathrm{Cu}$ and $\mathrm{Zn}$ ), vitamins (A, C, and $\mathrm{E}$ ), and binding proteins (e.g., LF) (165).

In vitro studies suggest that human LF decreases the intensity of free radical processes (166), and adiponectin $(4.2-87.9 \mathrm{ng} / \mathrm{ml})$ enhances the antioxidative potential of cells to counteract the increase in intracellular reactive oxygen species (ROS) during the hypoxia-reoxygenation-induced apoptosis (167). Animal studies showed that lysozyme participates in the suppression of ROS and strengthens resistance to chronic exogenous oxidant stress (168).

Melatonin is interesting in the context of milk bioactive compounds due to its pleiotropic actions. Its protective effects have been demonstrated against cellular aging due to its antioxidant effects stimulating the expression of SOD, catalase, and GPx (169). Tryptophan found in breast milk and its metabolites would seem to possess strong antioxidant properties and good anti-product abilities (170). Lozano et al. (171) in 2014 found the antioxidant capabilities of other valuable molecules naturally found in human milk, such as coenzyme Q10, tocopherol, fatty acids, and IL-10. Breast milk contains adequate amounts of selenium, a necessary microelement for important antioxidant enzymes, defined precisely as Sedependent molecules, including GPx and glutathione reductase.

\section{Cells}

The heterogeneous mixture of breast milk cells (Figures 1, 2) includes leukocytes, epithelial cells, stem cells, and bacteria. Certainly, cells of human milk are not insignificant components, but their function is still unclear. Leukocytes are the most widely studied cell types due to their protective properties and their ability to infiltrate the infant's tissue. About $80 \%$ of the cells in early milk are breast milk macrophages, and phagocytosis of human milk components transforms these monocytes into potent breast milk macrophages with unique functional features, including the ability to differentiate into DCs that stimulate infant T-cell activity $(4,169,171-173)$. This capability provides broadly powerful protection against pathogens while stimulating the development of the infant's own immune system.

Human breast milk is rich in microRNAs (miRNA), and so far, more than 386 different miRNAs were identified (174). Compared with other body fluids, milk is one of the richest sources of miRNA, which are present in all three fractions of human milk, including cells, lipids, and skim milk (175). miRNA plays a key role in regulating the immune system, including $\mathrm{T}$ and $\mathrm{B}$ cell development $(176,177)$, release of inflammatory mediators (178), proliferation of monocytes and neutrophils (176), and differentiation of macrophages and DC. mRNA might be engaged in the epigenetic regulation of stem cells fate and function $(178,179)$.

Speaking of stem cells, they are being studied, but their roles are presently little known. It is considered that they can play a cardinal part in the repair of tissue or organ damage caused by several types of insults (180). This is also a really important factor to recto, considering that the deleterious effects of COVID19 infection are precisely related to epithelial damage and the consequent repair mechanisms are sometimes seriously distorted $(181,182)$.

\section{BREAST MILK AND VIRAL INFECTION}

After considering all the active components of breast milk, the second part of this study wants to underline their major antiviral effects (Figure 3).

\section{Breastmilk and Respiratory Syncytial Virus}

Literature data confirm nowadays that viral respiratory infections are the major cause of children hospitalization worldwide, and a lot of studies were conducted to demonstrate that breastfeeding has an important preventive role, supporting the postulate that the risk of infant morbidity for viral acute respiratory diseases is negatively associated with the duration of breastfeeding (183). Some authors suggest that human milk reduces the risk of respiratory infection in newborns and the oxygen medication during bronchiolitis because the decrease of chemokine concentration in the airway and the increase of anti-inflammatory mediators like IFN- $\gamma$ probably mean stronger immune response in breastfed infants $(184,185)$. A crucial role in human milk was played by LF that may decrease the production of chemotactic cytokines and neutrophil chemotaxis (186). Also, oligosaccharides and procathepsin D can influence the neutrophil activity modifying the neutrophil adhesion, infiltration, and activation (187). The relationship between mother and baby during breastfeeding is bidirectional; indeed, the mother exposure to the baby's infection increases the production and the passage of anti-inflammatory constituents through the milk $(7,188,189)$.

\section{Breast Milk and HIV Infection}

A lot of studies demonstrate that innate and adaptive immune mediators of human milk inhibit the HIV infection, preventing the mother-to-child transmission and inhibiting the virus activity; an important role is played by HMOs, LF, and other innate factors (5). Specifically, HMOs block the binding of $H I V$ 


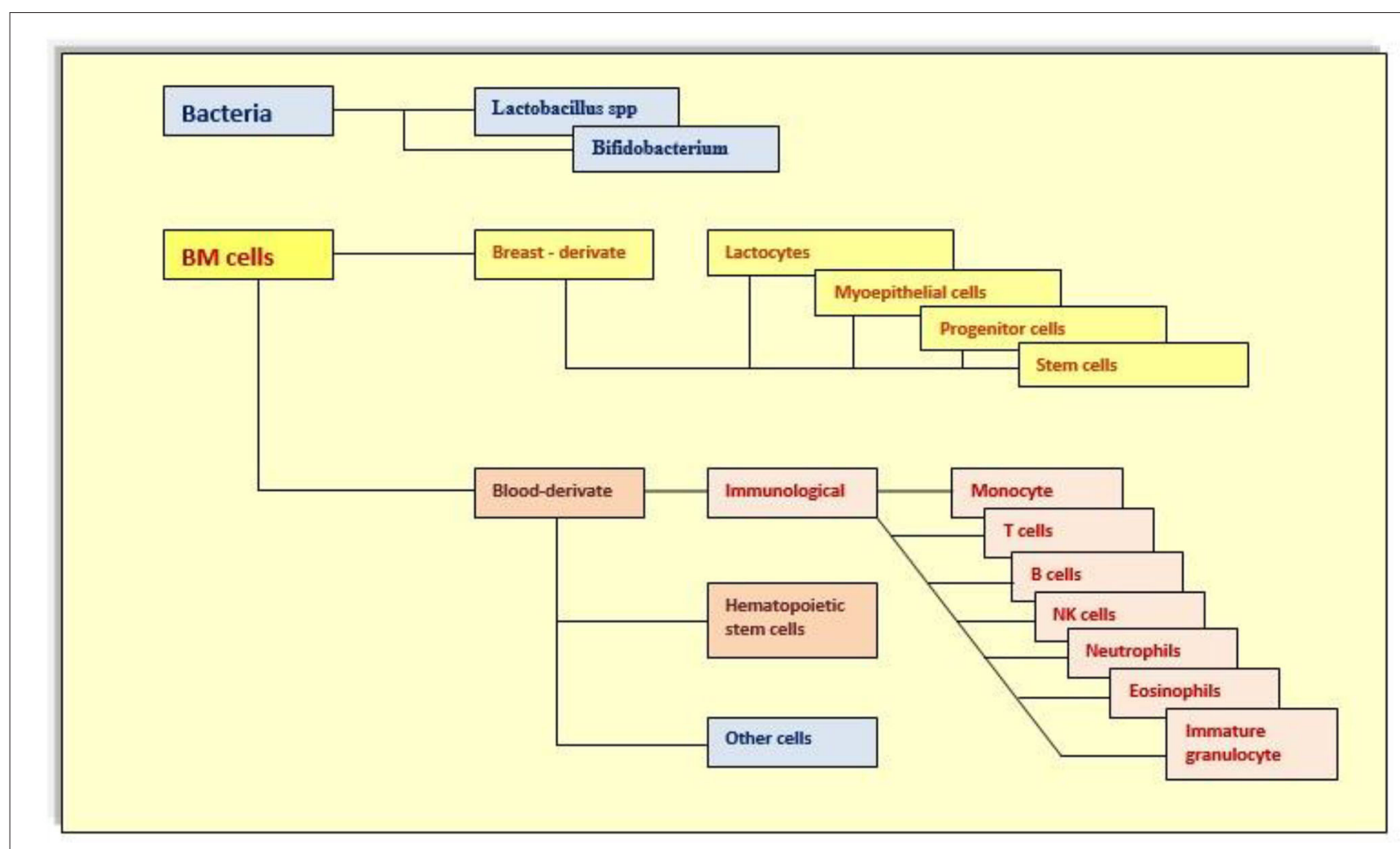

FIGURE 2 | Cells in human milk.

on human DCs; they also directly modulate the immune cell responses (1). LF inhibits the virus interaction with CD4 receptor, reducing inflammation (190). Soluble TLRs (sTLRs) interact with specific HIV structural proteins, inhibiting the activation of the virus (191). Breastfeeding nowadays represents one of the most successful prevention interventions for $H I V$ (5).

\section{Breastfeeding and Gastrointestinal Infections}

Noroviruses are the most frequent causes of acute gastroenteritis among children, and human milk with its HMOs is able to protect breastfed infants against this infection. Recent studies demonstrate that the Norovirus interacts with histo-blood group antigens (HBGAs), and this binding is important for virus attachment to cells causing infection $(192,193)$. HBGAs have been found in saliva and on epithelial cells, and some authors demonstrate that HMOs mimic their structure (194). Weichert et al. (193) in their study showed how HMOs, specifically fucose, can block the HBGA binding site, inhibiting the virus interaction. To account that human milk contains 20 to $30 \mathrm{mg} / \mathrm{l}$ of fucose, the authors declare that breastfeeding works as a norovirus antiviral $(183,193)$. It is also well-known that rotavirus infection represents the most dangerous infection during childhood, specially between 6 months and 2 years; it can cause a very large number of gastroenteritis episodes and hospitalization, and it can be estimated that the virus can cause approximately 500,000 deaths in children under 5 years $(4,195)$. The infection is due to an interaction between the virus and an enterocyte, resulting in alteration of absorption and secretion of the intestinal tract (196). The World Health Organization and the major scientific society recommended that infants should be exclusively breastfed for the first 6 months (197), and in a recent review, the authors showed an interesting positive role of breastfeeding in reducing rotavirus infection prevalence among exclusively breastfed children (196). HMOs again have a crucial role. A recent clinical study has demonstrated that the rotavirus infection mechanism is similar to that of the norovirus one; indeed, an in vitro study documented that the rotavirus interacts with some type of HBGAs (32). HMOs at the same time block the binding of rotavirus to epithelial cells and modulate the apoptosis and the differentiation of epithelial cells, modulating intestinal susceptibility (198). HMOs, in norovirus infection, might work as specific antivirals, blocking the HBGA binding site and at the same time blocking the binding of rotavirus to epithelial cells $(8,187,198,199)$. According to some authors, HMOs play together with newborn microbiota, resulting in a better infection protection $(200,201)$. Therefore, the bioactive human milk mediators can improve the immune response after vaccine (198). During the last 20 years, scientists conducted a lot of studies about other human milk constituents and their impact on rotavirus infection. Before HMOs, the attention was for mucin proteins, butyrophilin, lactadherin, and LF. A lot of studies have shown the antirotavirus 


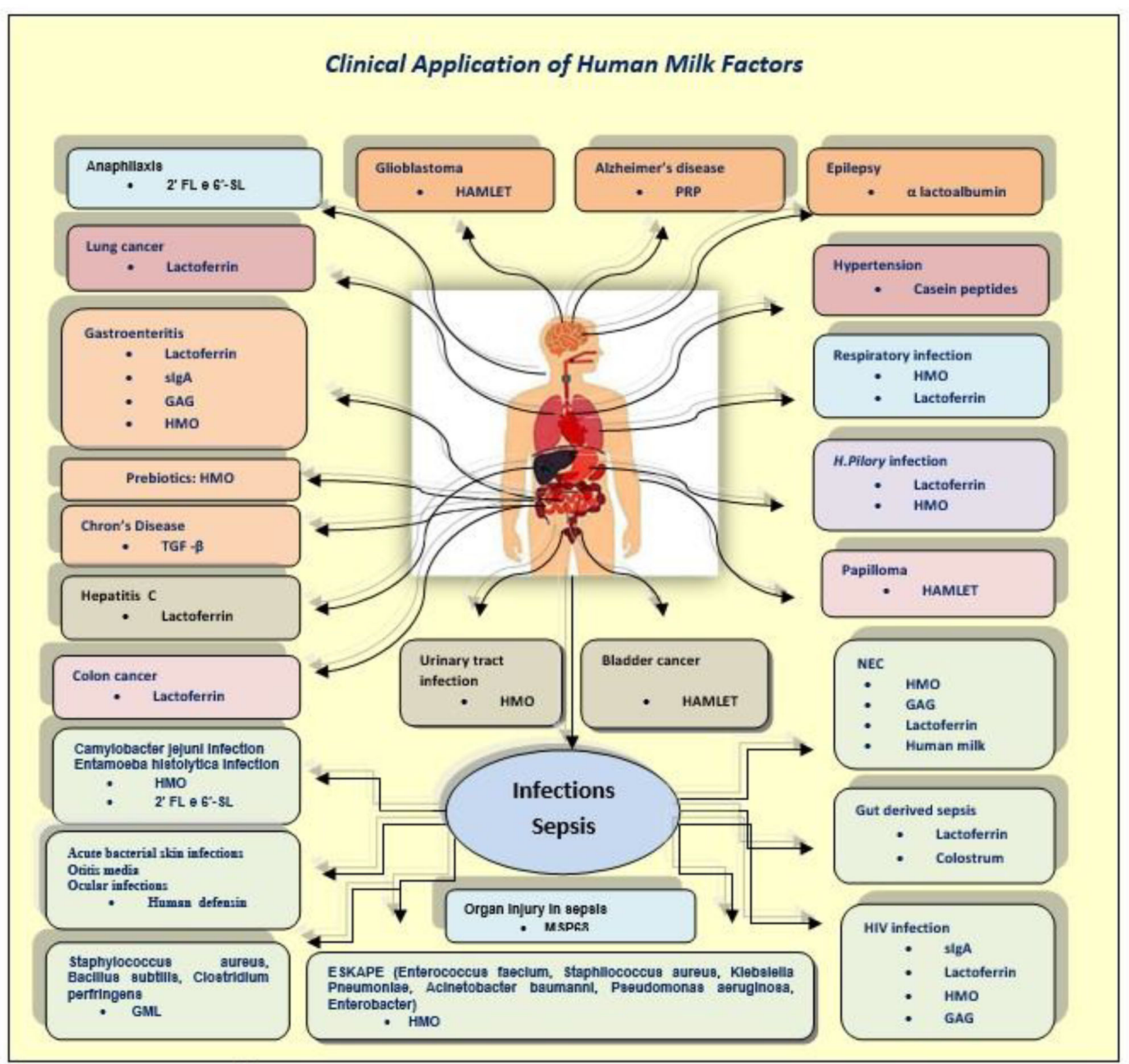

FIGURE 3 | Da RJH 2014 modified.

activity of these components, reducing virus infectivity and, in some cases, the interaction between the cells and the virus (202). Human milk oxysterols have broad antiviral activity inhibiting viral replication and are now considered involved in the innate immune response against viruses; in vitro studies have demonstrated a powerful activity against rotavirus and rinovirus and are considered an emerging class of antiviral effectors $(102,103)$.

Breast milk, in conclusion, represents a strong protection against a lot of enteropathogens because it is rich in immune and non-immune mediators; a large number of studies showed an important positive effect in diarrhea morbidity and mortality due to the mixture of all immunologic components (203).

\section{Breastfeeding and Influenza Virus}

Influenza viruses are three types of pathogens, A, B, and C; type $\mathrm{A}$ is the most frequent cause of influenza in humans, in children too. It can cause respiratory symptoms so the upper and the lower respiratory tracts are the specific infection sites. Generally, after the virus interaction with the respiratory tract, serum immunoglobulins are produced. It is known that these immunoglobulins protected the newborn through breast milk, but an important role is played by other immune mediators like antiviral cytokines that modify the respiratory epithelial cells blocking the interaction with virus (204). Prostaglandins PGE2 and PGE $\alpha$ inhibit the growth of parainfluenza virus 3 (205). 
LF can inhibit virus absorption and cell penetration too (206). Breast milk lipoproteins can cause cell lysis. Macrophage, IL, and IFN-1 modulate the immune response against viruses; in fact, a study demonstrates that high levels of IFN in human milk can mitigate influenza virus infections, especially H1N1 (204). Because of its structure, influenza virus interacts with HMOs, modifying virus affinity for epithelial cells (207). The importance of breast milk for infection prevention is due mostly to its biodynamic constituents.

In the last years worldwide, there were big viral infection outbreaks like avian influenza, Ebola virus, Zika virus, MERS coronavirus, and nowadays the big pandemic COVID-19. Mothers infected were always encouraged to breastfeed.

According to literature data, breast milk can be a source of viral infection, for example, Zika infection and others, but the bioactive mediators carried by milk can directly modulate the real infectivity of viruses $(208,209)$. The potential risk of infection should be compared with the large benefits of breastfeeding during the first 6 months of life.

\section{SARS-CoV-2 and Breastfeeding}

Generally, 229E, OC43, and HKU1 coronavirus are the common causes of cold. Instead, Middle East respiratory syndrome coronavirus (MERS-CoV), SARS-CoV, and the new SARS-CoV-2 cause severe respiratory symptoms with high pathogenicity and mortality in humans; SARS-CoV-2 generated a new pandemic disease called COVID-19 or coronavirus disease 2019 (210). This infection was due to a new type of coronavirus; these viruses have rapidly evolved and changed during the past years. SARS-CoV-2 is an enveloped, single-strand RNA virus that infected humans and also animals. They are able to alter the tissue specificity and to mutate rapidly in different epidemiological situations $(211,212)$; this genome is similar to the other coronaviruses and encodes the structural protein involved in viral replication, as spike (S), envelope (E), nucleocapsid $(\mathrm{N})$, and membrane (M) as well as non-structural and accessory proteins. This will result in a large number of suitable therapeutic targets (213). Literature data suggest that the spike protein mediates attachment of the virus to the cell surface by interaction with its glycoprotein receptor $(211,212)$. A recent study found that a metallopeptidase, the angiotensin-converting enzyme 2 (ACE-2), could represent a receptor for the virus mediating the entry into host cells; to facilitate this entry, a large number of coreceptors are required (213). Moreover, taking into account the similarities between $\mathrm{CoV}$ and $\mathrm{CoV}-2$, the crucial role of the heparan sulfate proteoglycans (HSPGs) on the cell might be thought like a mediator for virus binding and entering the host cell.

Nowadays, the new SARS-CoV-2 can cause a severe respiratory disease with fever, dry cough, severe dyspnea, and in some cases diarrhea; this clinical manifestation can evolve into pneumonia, metabolic acidosis, septic shock, bleeding, and unfortunately death $(214,215)$. In particular, SARS-CoV-2 has a high rate of contagiousness, and it can be transmitted through direct contact, aerosol droplets, and fecal-oral way, and both symptomatic patients and asymptomatic ones can spread viruses (216). Little is known about maternal-fetal transmission; during SARS-CoV, studies confirmed the possibility of vertical transmission, and pregnancy has been complicated by spontaneous abortion, oligohydramnios, and intrauterine growth restriction (IUGR) probably due by fetal thrombotic placenta vasculopathy with fetal vascular malperfusion (217). Stumpfe et al. (218) in their review suggest that CoV infection after the first trimester can reduce the placenta function. Limited information about MERS infection suggests better outcome; only 13 cases were reported (219). Recent studies documented that there is no evidence of transplacental transmission (144, 220-225), but more data are needed and some authors reported COVID-19 positive test $48-72 \mathrm{~h}$ after birth $(226,227)$. For real, it is unclear how CoV-2 interacts with the fetus during labor and delivery (228).

Important for the transmission are perinatal and postnatal routes through aerosol and droplets. For now, any evidence of the presence of CoV-2 in breast milk, but antibodies against the virus have been found. So, United Nations Children's Fund (UNICEF), WHO, Centers for Disease Control and Prevention (CDC), and other societies suggest to continue breastfeeding, but it is important to take all the respiratory precautions to prevent the spread of the virus (228). CDC underlines that the virus has not been found in human milk, and for now, it is unknown if affected mothers can transmit COVID-19 through their milk, so breastfeeding and the provision of human milk are strongly recommended by scientific organizations. To account for the benefits of breast milk, and the lack of evidence about the presence of the virus in the milk, it is important to continue breastfeeding with the necessary precaution like facial mask, washing hands, and disinfecting contaminated surfaces. Some authors suggest personalized prenatal intervention to explain to family the important role of human milk with its antibodies, HMOs, LF, and other mediators for the prevention of viral infection (229).

The American Academy of Pediatrics (AAP) (230) affirmed that breastfeeding can help to protect newborns against viral infection not only by the active mediators of human milk but also by avoiding the potential spread of virus through the handling of formula, bottles, and other supplies (231).

It has been reported that the immune response is essential to inhibit viral infection; this mechanism is mediated by genes that encode active mediators, like LF (232). During SARS-CoV, Reghunathan et al. (233) demonstrated increased levels of LF that through NK cell activity stimulated the immune response. LF blocks the interaction between CoV and HSPGs, inhibiting the binding with host cells (234). Moreover, it blocks virus spike protein binding with ACE-2, inhibiting the attachment and the fusion between virus and host cells (235). In the same way, LF could interfere with CoV-2 HSPGs and ACE-2 pathways. The study of Lang et al. (232) suggests that LF can inhibit the entry of SARS pseudovirus into host cells. It is known that the virus adhesion to the host cell is necessary for infection, and CoV2 utilizes glycoprotein and ACE-2 metallopeptidase receptors; in the presence of receptor analogs, there will be a competition between these mediators and the virus. HMOs could interfere with virus binding, reducing the change of developing disease. No data are available, but probably future research could confirm this theory as in the case of influenza viruses. Pandey et al. (207) demonstrated that HMOs have an antiviral activity against a 


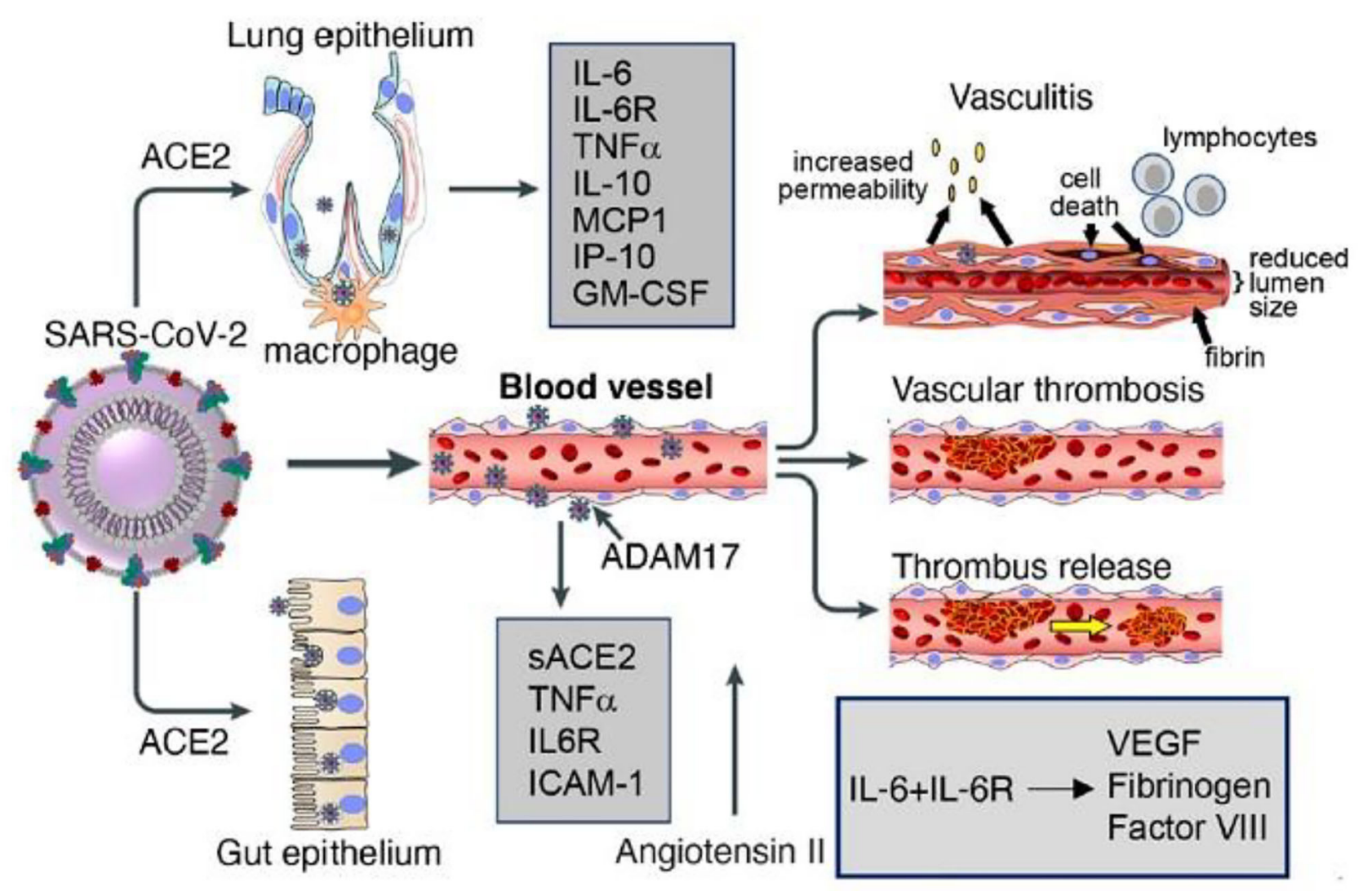

FIGURE 4 | Lung and gut epithelia, macrophages, and vascular endothelia are infected by SARS-COV-2 in COVID 19. Soluble (s) ACE2, inflammatory cytokines, cytokines receptors, chemokines and other factors are released by virus binding and cell infection. Vascular pathology in COVID 19 includes vasculitis, associated with endothelial cell death, increate vascular permeability, recruitment of inflammatory lymphocytic cells, fibrin deposition and reduction of lumen size; vascular thrombosis; and vascular embolization. Labò et al. (236).

large number of avian influenza viruses, blocking the pathogen attachment to the host cells maybe in the same way this human milk mediators could inhibit the CoV-2 adhesion with host cells.

\section{BREAST MILK FACTORS: A NEW TOPIC OF COVID RESEARCH}

In this section, we reported the evidence in vivo and in vitro that shows how the bioactive components of breast milk are capable of performing functions theoretically useful in all pathogenic events recognized and described in the COVID disease (Table 1, Figure 4). Based on mechanisms regarding the effects of the milk factors, specific treatments could be developed in order to regulate the action of the immune system stimulating the specific contrast of the virus and blocking the start of a disproportionate and harmful immune response, in this disease, which continually shows new clinical aspects.

\section{Virus Invasion, Replication, and Release}

CoV-2 gets inside the respiratory system through droplets (237). The viral glycoprotein on its capsid, the "spike protein," binds the ACE-2 receptor and the RNA genome enters the host cell, mostly the alveolar cells, via receptor-mediated endocytosis. ACE-2 is a transmembrane protein expressed by lung alveolar epithelial cells, but also enterocytes and vascular endothelial cells (236). The spike protein is composed of two (S1 and S2) subunits. Once S1 binds the receptor-binding domain (RBD) of the ACE-2 receptor on the target cell, the HR1 and HR2 domains of the second subunit bring the cell and virus membranes in proximity to each other in order to facilitate their fusion and consequently the infection. Two spikes have been shown to bind an ACE-2 dimer at the same time. Simultaneously with the binding of the spikes to the ACE-2 receptor, the serine proteases type II transmembrane serine protease (TMPRSS) and furin carry out a modification of S2 structure, which allows the virus penetration into the host cell. Both endothelial cells and pneumocyte II express high concentrations of ACE-2 and TMPRSS. TMPRSS2 and furin are both essential for proteolytic activation and spread of SARS-CoV-2 in human airway epithelial cells $(238,239)$.

LF blocks the interaction between CoV and HSPGs, inhibiting the binding with host cells; moreover, it blocks virus spike protein binding with ACE-2 inhibiting the attachment and 
the fusion between virus and host cells. Therefore, LF has been listed as a drug candidate for the treatment of SARS disease $(232,234)$. Based on this concept, an ongoing clinical trial is studying the effect of a dual combination treatment with local solubilized intranasal spray formulation and oral administration (145).

Milk produced by infected mothers is a source of anti-SARSCoV-2 IgA and IgG and neutralizes SARS-CoV-2 activity (240, 241). Mothers have unique profiles in their milk sIgA antigenbinding domains, the part of the antibody that recognizes and binds to the SARS-CoV-2 virus. It would be useful to determine whether this variability relates to which part of the virus the antibody recognizes, to the neutralization ability of the antibody, or to the severity of the illness in the mother (242).

However, other researchers have verified that the main antimicrobial components of breast milk, such as LF and IgA antibody, showed limited anti-coronavirus activity, but whey protein is a direct-acting inhibitor of SARS-CoV-2 infection by blocking viral attachment, entry, and even post-entry viral replication. This suggests that other factors of breast milk may play the important anti-COVID-19 role (243). Even with the limits of a preliminary and preprint report, and with the necessity of further investigation of its molecular mechanism of action in the context of SARS-CoV-2 infection, the data are interesting.

\section{Hyperimmunity and Cytokine Storm}

The interaction between the viral antigens and the host immune cells (244) results in activation of pro-inflammatory responses as vasodilation, an increase of vascular permeability and accumulation of humoral factors.

\section{Toll-Like Receptor Pathway}

The elevated inflammatory response against CoV-2 is represented by an abundant expression of pro-inflammatory cytokines, the products of the TLR signaling pathway $(245,246)$. TLR4 possesses a strong binding affinity to spike protein followed by TLR6 and TLR1.

Therefore, the interaction between TLR4, the most efficient innate immune receptor that induces proinflammatory responses after binding with the pathogenic ligand (247), and spike protein could be one of the reasons behind the immunopathological manifestation of COVID-19 $(248,249)$. The interaction could be more complex, involving TLR3, TLR5, TLR6, and TLR7 (245); specifically, TLR7 agonist has been proposed as a therapeutic option (250).

In a study with TRAM-TLR3/TLR4-deficient mice, it was demonstrated that affected mice are more susceptible to SARS$\mathrm{CoV}$ than wild type; mice deficient in the TLR3/TLR4 showed increased weight loss, increased mortality rate, reduced lung function, increased lung pathology, and higher viral titers (251). Some authors have suggested a line of research that aims to identify signaling pathways altered during SARS-CoV2 infections, and this may help to unravel the most relevant molecular cascades implicated in biological processes mediating viral infections and to unveil key molecular players that may be targeted (252).
Aberrant pro-inflammatory cytokine, chemokine, and IFNstimulated gene signaling pathway were noted following infection in modified mice that were similar in human patients with poor disease outcomes following a SARS$\mathrm{CoV}$ or MERS-CoV infection (251). These findings highlight the importance of TLR adaptor signaling in generating a balanced protective innate immune and targeting aberrant monocyte/macrophage activation to reduce the severity of the coronavirus-induced symptomatology.

There are two groups of TLR modulatory human milk components. One group includes lacto- $N$-fucopentaose III (LNFP III) and sialyl $(\alpha 2,3)$ lactose (3-SL), which increase TLR signaling. Another group includes sTLRs, soluble cluster of differentiation (sCD), lactadherin, and LF, $\beta$-defensin 2, and several oligosaccharides, which depress TLR signaling pathways (31).

\section{Pro-Inflammatory Feedback Loop}

CoV-2 infects the epithelial and endothelial cells and alveolar macrophages, triggering the generation of pro-inflammatory cytokines and chemokines (236, 253), including IL-6, IL-10, IL-1, IL-8, TNF- $\alpha$, macrophage inflammatory protein (MIP1 $\alpha$, MIP1 $\beta$, and MIP1), that recruit immune cells, neutrophils, and macrophages to the site of infection. As in other lung infections, severe lung inflammation is perpetrated by this invasion of neutrophils and macrophages into the alveolar space, which promotes further inflammation and establishes a pro-inflammatory feedback loop that results in damage to the endothelial and epithelial lung layers (254, 255). Similarly, during influenza virus and $R S V$ infections, increased numbers of neutrophils in the lungs contributed to worse outcomes (256-258).

Human milk contains a well-developed anti-inflammatory system that includes several bioactive factors.

The HMOs of human milk inhibit the adhesion, mediated by lecithins, of leukocytes to the endothelium, a critical step in the expansion of the inflammation $(1,50)$, and suppress the infiltration of leukocytes and the immune response.

IL-10 of breast milk is a powerful anti-inflammatory, since it is able to inhibit the activity of Th1 effector cells, NK cells, and macrophages (62) and the production of several pro-inflammatory cytokines (IL-1, IL-6, IL-8, and TNF- $\alpha$ ), thus attenuating the immune response. Human breast milk dramatically suppresses IL-8, the pro-inflammatory cytokine that is significantly in the severe form of the CoV-2 disease $(236,253)$.

Milk fat globule-EGF-factor VIII (MFG-E8) inhibits excessive neutrophil infiltration of organs, leading to moderate attenuation of organ injury and an improved survival rate in septic mice (259).

The inflammatory environment in COVID-19 enhances the production of reactive oxygen species (ROS), impairs lung barrier function, and increases vascular permeability, and, where ARDS is prolonged or unresolved, it can lead to fibrosis (260). Antioxidants are a significant part of the anti-inflammatory system in human milk and can counteract just the excessive production of ROS due to hyperoxia, reperfusion and/or inflammation, and ROS-induced tissue damage (166). 


\section{Cytokine Storm}

The most serious aspects of the CoV-2 disease are related to an excessive immune reaction in the host called sometimes "cytokine storm" (143, 236, 245, 260-263). The effect is an extensive tissue damage. The protagonist of this storm is IL-6. It is produced by activated leukocytes and acts on a large number of cells and tissues. It is able to promote the differentiation of Blymphocytes and the growth of some categories of cells, inhibit the growth of others, and stimulate the production of acute-phase proteins. In the lungs of human patients with fatal SARS, elevated levels of IL-6 were detected (264). In CoV-2 disease, increased levels of IL-6 were significantly associated with high hs-TnI levels (265), a cardiac-selective biomarker of myocardial infarction and injury (266).

However, anti-inflammatory cytokines such as IL-4 and IL-10 are also increased in COVID-19 patients, and their levels are also related to disease severity $(143,267)$. This demonstrates the close relation between pro- and anti-inflammatory pathways. Breast milk factors have known and unused implications in the complex system of inflammation.

Experimental studies proved that adiponectin expression is negatively regulated by pro-inflammatory cytokines, including IL- 6 and TNF- $\alpha$, whereas adiponectin modulates the action and production of TNF- $\alpha$ in various tissues, while hypoadiponectinemia is associated with increased IL- 6 levels $(268,269)$.

Intraperitoneal injection of human milk hyaluronan suppresses immune activation in a murine model of colitis (270) and promotes the proliferation of anti-inflammatory IL-10-secreting Tregs (271).

Supplementation of the formula with TGF- $\beta 2$ downregulated the pro-inflammatory cytokines as well as the number of activated lymphocytes, eosinophils, mast cells, CD80, and CD86 DCs. TGF-b2 suppresses macrophage inflammatory responses in the developing intestine and protects against inflammatory mucosal injury. Enterally-administered TGF- $\beta 2$ protected mice from experimental NEC-like injury (272). Feeding formula deficient in TGF- $\beta 2$ resulted in accumulated IL-18 protein release from intestinal epithelial cells and IL-18 mRNA upregulation $(273,274)$.

Enterocyte IL-18 is upregulated in Th1-associated diseases such as Crohn's disease (275).

The remission rates following the use of TGF- $\beta$-based preparations for the treatment of Chron's disease in adult patients are higher than $80 \%$, and when correlated to traditional treatments with cortisone, they were equally effective but with fewer side effects and a better nutritional profile (277).

It was demonstrated that posttreatment with MFG-E8derived peptide (MSP68) significantly reduces the inflammatory response, decreasing IL-6 levels, and attenuates organ damage in septic mice (259). It was also shown that MSP68 treatment improves the histopathology and the integrity of the lung tissue and decreases lung apoptosis. MFG-E8 has been referred to as a potent therapeutic agent in sepsis-associated acute kidney injury by improving renal functions. The treatment with recombinant mouse MFG-E8 attenuated the renal function biomarkers, which was accompanied by the reduction of renal tissue histological damage and inhibition of the expression of pro-inflammatory cytokines, chemokines, and cell adhesion molecules in the renal tissues (259).

\section{Hypercoagulation}

Another pathogenic event of the COVID-19 is procoagulant effect and diffuse thrombosis with particular involvement of the pulmonary but also cardiac vessels (236). Evidence supports the strong prognostic importance of the coagulopathy impact on affected patients $(182,216,278,279)$.

An additional LF property that was identified in an interesting study is to act as a natural and specific inhibitor of the uPA-mediated plasminogen activation. High levels of LF were reported to be secreted by apoptotic cells (140). In apoptosis, LF might be necessary to downregulate the extracellular plasmin activity to avoid unwanted degradation of the surrounding tissue, inappropriate cell migration, or activation of proenzymes.

This topic is relevant if we consider that pulmonary embolism, intestinal ischemia, and vasculitis are serious manifestations of COVID-19 (280-282) (Figure 4).

A hypothetical possible role could be played also by lactadherin that could function as an anticoagulant and thereby regulate hemostasis, thanks to the homology of the $\mathrm{C} 2$ domain to coagulation factors VIII and V, and the competition between them for platelet membrane-binding sites (152).

\section{Multi-Organ Damage}

The endothelium may appear to be the battlefield for COVID19 (283). Systemic inflammatory vasculitis, secondary to endotheliosis, emerges to be the most feared complication in a SARS-CoV-2 infection, and the endothelium could be a secondary target of SARS-CoV-2 infection. The ubiquitous distribution of ACE-2 in blood vessels may underlie the multi-organ pathology of COVID-19 (265). The endothelial dysfunction results in reduced vasodilation, pro-inflammatory state, and prothrombin properties (159).

Several factors of human milk have shown protective and reparative abilities of the endothelium (1, 18). For example, some data identify that endothelial TLR4 critically regulates intestinal perfusion, leading to NEC, and reveal that the protective properties of breast milk involve enhanced intestinal microcirculatory integrity (284). Endothelial TLR4 activation impairs intestinal microcirculatory perfusion in necrotizing enterocolitis also via eNOS-NO-nitrite signaling (endothelial nitric oxide synthase). HMO-2'FL protects against NEC in part through maintaining mesenteric perfusion via increased eNOS expression (285).

In vitro and ex vivo animal studies have suggested an important role for milk-derived cytokines such as TNF (59), MFG-E8 (286), and IL-6 (96) on intestinal epithelial repair. Numerous functions in wound repair, coagulation, and host defense have been attributed to glycosaminoglycans (chondroitin sulfate, heparin sulfate, hyaluronan dermatan sulfate) (287), and many clinical studies have demonstrated the effectiveness of glycosaminoglycan preparations in enhancing wound healing (288). 

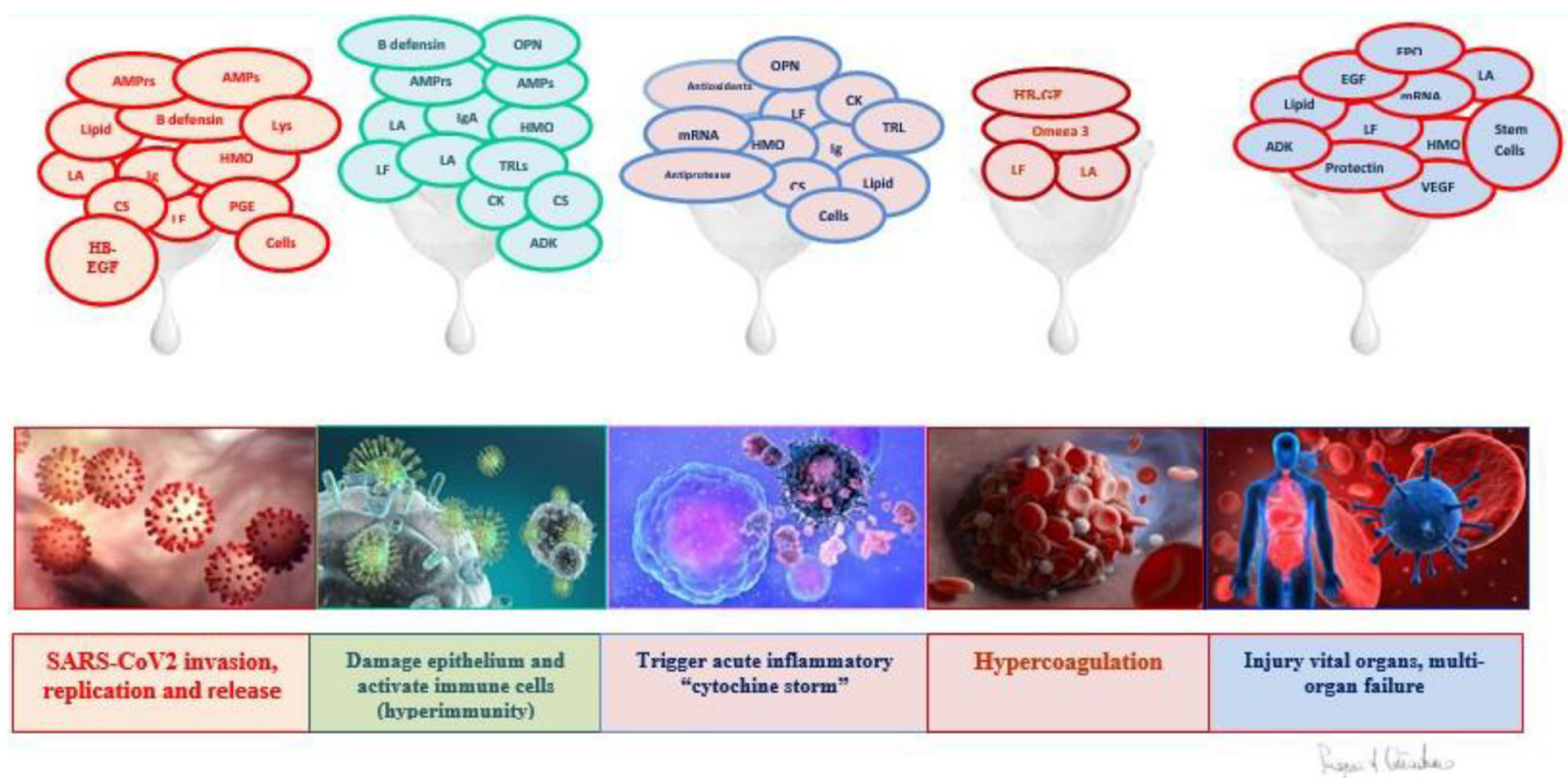

FIGURE 5 | Functions of breast milk factors in pathogenetic events of COVID disease. LF, lactoferrin; LA, Lactadherin; CK, Cytokines; CS, Chondroitin Sulfate; HMO, Oligosaccharides; AMPrs, Antimicrobial Proteins; AMPs, Antimicrobial Peptides, OPN, Osteopontin; TGF $\beta$, transforming growth factor; TNF $\alpha$, Tumor Necrosis Factor; EGF, Epidermal Growth Factor, HB-EGF, Heparin Binding EGF-like growth factor, VEGF, Vascular Endothelial Growth Factor; EPO, Erythropoietin, Lipids: omega-3 PUFAs, Omega-3+omega-6 PUFAs, FFAs: Free Fatty Acids, ADK: Adipokines, Ig: SlgA: Secretory IgA, IgM, IgG, Lys: Lysozyme, B defensing, TLRs: Toll-Like Receptor, Antioxidants, Anti-proteases ( $\alpha$-1-antitrypsin, $\alpha$-1-antichymotrypsin, elastase inhibitor), mRNA: MicroRNA, Cells: Lactobacillus Spp, Bifidobacterium Spp, Leukocytes, Stem cells, Protectin, PGE1/E2: Prostaglandin E1/E2.

Just about the reparative capacity, we recall the growth factors present in breast milk, as EGF promotes the growth and maturation of the fetal pulmonary epithelium and accelerates wound healing andVEGF, whose main role is the mediation of angiogenesis (27). Enteral EGF administration can increase the expression of the anti-apoptotic protein Bcl-2 and decrease levels of the pro-apoptotic protein Bax. The role of EGF in balancing apoptosis regulators provides implications of an opportunity for future therapeutic strategies to protect the intestinal barrier from injury in NEC $(289,290)$.

Growth factors are also secreted by breast milk stem cells (180). In fact, the concept for the potential therapeutic benefit of human milk stem cells (HMSCs) is largely based on the results of studies where HMSCs were cultured and differentiated in vitro followed by identification of the growth factors that they secreted (291, 292). For example, of particular importance for stroke therapy is the ability of certain subpopulations of these differentiated cells to produce VEGF and HGF and a protocol for culturing breast milk-derived cells that increase the production of these factors, which has been established (293). The regenerative power of HMSCs has not yet been defined, but the studies are very promising.

\section{Human Milk Opportunities}

During this period, the scientists are studying the disease caused by SARS-CoV-2, how bioactive factors of milk can modulate vertical transmission or otherwise affect the clinical presentation/disease trajectories of newborns. Milk from mothers who have COVID-19 could be a source of antibodies directed against the virus. Data indicate that there is strong $\operatorname{sIgA-}$ dominant SARS-CoV-2 immune response in human milk after infection in the majority of individuals (294). As with plasma antibodies, these maternally derived antibodies offer the potential as a therapy to help seriously ill patients (242).

But, since the set of all the factors would seem more effective in protecting and combating the infection, Dutch researchers (295), instead of isolating antibodies, plan to use whole milk as therapy and are studying various pasteurization techniques that make milk safe but also retain all important immune components (SARS-CoV-2 Research Highlights the Importance of Human Milk Immunobiology. International Milk Genomics Consortium, July 2020).

\section{Multifunctionality}

Most of the protective components of human milk may interact synergistically with each other or with factors related to the mucosal or systemic immune response (99). Moreover, the main factors are multifunctional and exhibit both antimicrobial and anti-inflammatory activities but also control of immune hyperactivity and some have simultaneously shown repairing skills (Figure 5). As demonstrated in some studies, multiple compounds that act through different mechanisms can exert combined protective and curative effects, and future 
investigations should evaluate the application of therapies consisting of a set of multiple components from milk (Figure 3).

Furthermore, since the majority of bioactive factors in milk have not yet been identified, characterization of novel factors in milk will open the door to the development of novel antimicrobial therapies.

Giving seriously ill patients human milk would allow them to take advantage of the synergistic activities of milk immune factors that have evolved to improve survival in vulnerable infants and young children.

\section{Tolerability}

Human milk factors are well-tolerated and practically free of side effects, and ongoing studies should be intensified while others should be activated $(276,277)$. Their efficiency should be the maximum expression of the antiviral, anti-inflammatory, and immune modulation functions during the complex course of COVID-19 or as protective factors for the entire population, especially that part which is at the greatest risk. A goal could be the discovery of factors capable to reduce the severe evolution of the disease and the use of respiratory assistance in intensive care.

\section{For the Infants}

All the infants of the world must be fed with breast milk; in this way, they may be protected against COVID-19. The breastfeeding must extend over a period of 2 years (at least), as indicated by the WHO. Human milk with its mediators represents a complex immune element, which varies its composition to meet the needs of the mothers and children. Where mother's milk is not available, the alternative for premature baby or newborns with pathologies must be represented by human milk donated to the Human Milk Banks, which, although pasteurized, retains most of its antiinfectious properties (e.g., total savings of HMOs and fatty acids). Whenever human milk substitutes are needed, formulas added to milk bioactive factors should be preferred.

\section{CONCLUSIONS}

In recent years, due to the significant number of viral disease outbreaks worldwide, vaccines and antiviral drugs to control the spread are unable to account for the mutation rates of viruses and are not developing fast enough compared to the exponential spread of the disease. Human milk with its bioactive factors offers a potent solution to prevent and fight life-threatening infections. Many data are available about the common viral infections; few data about MERS and $\mathrm{CoV}$ and emerging data about CoV-2 are published. Immunoglobulins, LF, and HMOs with many other active substances represent antiviral mediators against the new

\section{REFERENCES}

1. Hill DR, Newburg DS. Clinical applications of bioactive milk components. Nutr Rev. (2015) 73:463-76. doi: 10.1093/nutrit/nuv009

2. Oddy WH, Halonen M, Martinez FD, Lohman IC, Stern DA, Kurzius-Spencer $\mathrm{M}$, et al. TGF- $\beta$ in human milk is associated with wheeze in infancy. J Allergy Clin Immunol. (2003) 112:723-8. doi: 10.1016/S0091-6749(03)01941-9
$\mathrm{CoV}-2$ that underline the important role of breastfeeding and of human milk as a possible source of protective and therapeutic elements during this pandemic infection.

Some of the bioactive components of milk are undergoing preclinical evaluation in various disease models, others are subjected to active clinical evaluation, and others are in clinical use.

The puzzle of the COVID infection is being put together over this period of months; however, the knowledge of breast milk is a much larger and complex puzzle, which is missing several pieces, and that is why we talk about the "mystery of breast milk," and who knows, possibly from the study of this mystery, answers can be gained to help with the great epidemics of humanity.

\section{Limitations}

Only few data are available about the human milk's potential role against COVID-19, but a lot of studies documented the antiviral effect against many viruses.

The paper noted that some actions of breast milk factors were designed for use in adults, but most functions were described predominantly in the newborn.

The prevalent animal trial has been completed for other viral infections, and we need clinical trials for the better result.

\section{DATA AVAILABILITY STATEMENT}

The original contributions presented in the study are included in the article/supplementary materials, further inquiries can be directed to the corresponding author/s.

\section{AUTHOR CONTRIBUTIONS}

All authors contributed to the article and approved the submitted version.

\section{ACKNOWLEDGMENTS}

We would like to thank the researchers involved in the study of breast milk, who, thanks to the many advances made in the biological field, are documenting its exceptional nature in promoting health. We thank the Scientific Direction of the Casa Sollievo della Sofferenza Foundation, which is always open to the promotion of study and research in the field of breast milk. We thank the women who donate milk to our milk bank because they give us the opportunity to make our small contribution to the fact that the mystery of breast milk can be revealed in the not too distant future. O'Ryan ML, et al. Variability of human milk neutral oligosaccharides in a diverse population. J Pediatr Gastroenterol Nutr. (2000) 30:181-92. doi: 10.1097/00005176-200002000-00016

4. Riskin A, Almog M, Peri R, Halasz K, Srugo I, Kessel A. Changes in immunomodulatory constituents of human milk in response to active infection in the nursing infant. Pediatr Res. (2012) 71:220-5. doi: $10.1038 /$ pr.2011.34 
5. Henrick BM, Yao XD, Nasser L, Roozrogousheh A, Rosenthal KL. Breastfeeding behaviors and the innate immune system of human milk: working together to protect infants against inflammation, HIV-1, and other infections. Front Immunol. (2017) 8:1631. doi: 10.3389/fimmu.2017. 01631

6. Sankar MJ, Sinha B, Chowdhury R, Bhandari N, Taneja S, Martines J, et al. Optimal breastfeeding practices and infant and child mortality: a systematic review and meta-analysis. Acta Paediat. (2015) 104:3-13. doi: 10.1111 /apa.13147

7. Dixon DL. The role of human milk immunomodulators in protecting against viral bronchiolitis and development of chronic wheezing illness. Children. (2015) 2:289-304. doi: 10.3390/children20 30289

8. Liu B, Newburg DS. Human milk glycoproteins protect infants against human pathogens. Breastfeeding Med. (2013) 8:354-62. doi: $10.1089 / \mathrm{bfm} .2013 .0016$

9. Labbok MH, Clark D, Goldman AS. Breastfeeding: maintaining an irreplaceable immunological resource. Nat Rev Immunol. (2004) 4:565-72. doi: $10.1038 /$ nri1393

10. Kunz C, Rudloff S, Baier W, Klein N, Strobel S. Oligosaccharides in human milk: Structural, functional, and metabolic aspects. Annu Rev Nutr. (2000) 20:699-722. doi: 10.1146/annurev.nutr.20.1.699

11. Goehring KC, Marriage BJ, Oliver JS, Wilder JA, Barrett EG, Buck RH. Similar to those who are breastfed, infants fed a formula containing 2'-fucosyllactose have lower inflammatory cytokines in a randomized controlled trial. J Nutrition. (2016) 146:2559-66. doi: 10.3945/jn.116.236919

12. Ninonuevo MR, Park Y, Yin H, Zhang J, Ward RE, Clowers BH, et al. A strategy for annotating the human milk glycome. J Agric Food Chem. (2006) 54:7471-80. doi: 10.1021/jf0615810

13. Urashima T, Hirabayashi J, Sato S, Kobata A. Human milk oligosaccharides as essential tools for basic and application studies on galectins. Trends Glycosci Glycotechnol. (2018) 30:SJ11-24. doi: 10.4052/tigg.1734.1SJ

14. Puccio G, Alliet P, Cajozzo C, Janssens E, Corsello G, Sprenger N, et al. Effects of infant formula with human milk oligosaccharides on growth and morbidity: a randomized multicenter trial. J Pediatr Gastroenterol Nutr. (2017) 64:624-31. doi: 10.1097/MPG.0000000000001520

15. Hamosh M. Bioactive factors in human milk. Pediatr Clin North Am. (2001) 48:69-86. doi: 10.1016/S0031-3955(05)70286-8

16. Bao Y, Chen C, Newburg DS. Quantification of neutral human milk oligosaccharides by graphitic carbon high-performance liquid chromatography with tandem mass spectrometry. Anal Biochem. (2013) 433:28-35. doi: 10.1016/j.ab.2012.10.003

17. Bode L, Rudloff S, Kunz C, Strobel S, Klein N. Human milk oligosaccharides reduce platelet-neutrophil complex formation leading to a decrease in neutrophil $\beta 2$ integrin expression. J Leukoc Biol. (2004) 76:820-6. doi: $10.1189 /$ jlb.0304198

18. Lis-Kuberka J, Orczyk-Pawiłowicz M. Sialylated oligosaccharides and glycoconjugates of human milk. The impact on infant and newborn protection, development and well-being. Nutrients. (2019) 64:624-31. doi: 10.3390/nu11020306

19. Gnoth MJ, Kunz C, Kinne-Saffran E, Rudloff S. Human milk oligosaccharides are minimally digested in vitro. J Nutrition. (2000) 130:3014-20. doi: $10.1093 /$ jn/130.12.3014

20. Rudloff S, Pohlentz G, Borsch C, Lentze MJ, Kunz C. Urinary excretion of in vivo 13C-labelled milk oligosaccharides in breastfed infants. Br J Nutr. (2012) 107:957-63. doi: 10.1017/S0007114511004016

21. Smilowitz JT, O’Sullivan A, Barile D, German JB, Lönnerdal B, Slupsky CM. The human milk metabolome reveals diverse oligosaccharide profiles. $J$ Nutrition. (2013) 143:1709-18. doi: 10.3945/jn.113.178772

22. Ojo-okunola A, Cacciatore S, Nicol MP, du Toit. E. The determinants of the human milk metabolome and its role in infant health. Metabolites. (2020) 10:77. doi: 10.3390/metabo10020077

23. Chaturvedi P, Warren CD, Altaye M, Morrow AL, Ruiz-Palacios G, Pickering LK, et al. Fucosylated human milk oligosaccharides vary between individuals and over the course of lactation. Glycobiology. (2001) 11:365-72. doi: 10.1093/glycob/11.5.365

24. Bode L. Human milk oligosaccharides: Every baby needs a sugar mama. Glycobiology. (2012) 22:1147-62. doi: 10.1093/glycob/cws074
25. Newburg DS, Ruiz-Palacios GM, Morrow AL. Human milk glycans protect infants against enteric pathogens. Annu Rev Nutr. (2005) 25:37-58. doi: 10.1146/annurev.nutr.25.050304.092553

26. Tao N, Wu S, Kim J, An HJ, Hinde K, Power ML, et al. Evolutionary glycomics: Characterization of milk oligosaccharides in primates. J Proteome Res. (2011) 10:1548-57. doi: 10.1021/pr1009367

27. Thai JD, Gregory KE. Bioactive factors in human breast milk attenuate intestinal inflammation during early life. Nutrients. (2020) 12:581. doi: 10.3390/nu12020581

28. Newburg DS, He Y. Neonatal gut microbiota and human milk glycans cooperate to attenuate infection and inflammation. Clin Obstet Gynecol. (2015) 58:814-26. doi: 10.1097/GRF.0000000000000156

29. Buescher ES. Anti-inflammatory characteristics of human milk: How, where, why. Adv Exp Med Biol. (2001) 501:207-22. doi: 10.1007/978-1-4615-1371-1_27

30. Plaza-Díaz J, Fontana L, Gil A. Human milk oligosaccharides and immune system development. Nutrients. (2018) 10:1038. doi: 10.3390/nu10081038

31. He YY, Liu SB, Kling DE, Leone S, Lawlor NT, Huang Y, et al. The human milk oligosaccharide $2^{\prime}$-fucosyllactose modulates CD14 expression in human enterocytes, thereby attenuating LPS-induced inflammation. Gut. (2016) 65:33-46. doi: 10.1136/gutjnl-2014-307544

32. Morozov V, Hansman G, Hanisch FG, Schroten H, Kunz C. Human milk oligosaccharides as promising antivirals. Mol Nutrition Food Res. (2018) 62:1700679. doi: 10.1002/mnfr.201870046

33. Adams CA, Gutiérrez B. The benefits of human milk oligosaccharides in adult nutrition. Nutrafoods. (2018) 17:169-73. doi: 10.17470/NF-018-1021-4

34. Leach JL, Garber SA, Marcon AA, Prieto PA. In vitro and in vivo effects of soluble, monovalent globotriose on bacterial attachment and colonization. Antimicrobial Agents Chemotherapy. (2005) 49:3842-6. doi: 10.1128/AAC.49.9.3842-3846.2005

35. Charbonneau MR, O’Donnell D, Blanton LV, Totten SM, Davis JCC, Barratt MJ, et al. Sialylated milk oligosaccharides promote microbiotadependent growth in models of infant undernutrition. Cell. (2016) 164:85971. doi: 10.1016/j.cell.2016.01.024

36. Asakuma S, Hatakeyama E, Urashima T, Yoshida E, Katayama T, Yamamoto $\mathrm{K}$, et al. Physiology of consumption of human milk oligosaccharides by infant gut-associated bifidobacteria. J Biol Chem. (2011) 286:34583-92. doi: $10.1074 /$ jbc.M111.248138

37. Smith PM, Howitt MR, Panikov N, Michaud M, Gallini CA, Bohlooly YM, et al. The microbial metabolites, short-chain fatty acids, regulate colonic T reg cell homeostasis. Science. (2013) 341:569-73. doi: 10.1126/science. 1241165

38. Fukuda S, Toh H, Hase K, Oshima K, Nakanishi Y, Yoshimura K, et al. Bifidobacteria can protect from enteropathogenic infection through production of acetate. Nature. (2011) 469:543-9. doi: 10.1038/nature 09646

39. Vujkovic-Cvijin I, Dunham RM, Iwai S, Maher MC, Albright RG, Broadhurst MJ, et al. Dysbiosis of the gut microbiota is associated with HIV disease progression and tryptophan catabolism. Sci Transl Med. (2013) 5:193ra91t. doi: $10.1126 /$ scitranslmed.3006438

40. Kim $\mathrm{CH}$. Immune regulation by microbiome metabolites. Immunolog. (2018) 154:220-9. doi: 10.1111/imm.12930

41. Thorburn AN, McKenzie CI, Shen S, Stanley D, MacIa L, Mason LJ, et al. Evidence that asthma is a developmental origin disease influenced by maternal diet and bacterial metabolites. Nat Comm. (2015) 6:7320. doi: $10.1038 /$ ncomms 8320

42. Trompette A, Gollwitzer ES, Yadava K, Sichelstiel AK, Sprenger N, NgomBru C, et al. Gut microbiota metabolism of dietary fiber influences allergic airway disease and hematopoiesis. Nat Med. (2014) 20:159-66. doi: $10.1038 / \mathrm{nm} .3444$

43. Marsland BJ, Gollwitzer ES. Host-microorganism interactions in lung diseases. Nat Rev Immunol. (2014) 14:827-35. doi: 10.1038/nri3769

44. Tan J, McKenzie C, Vuillermin PJ, Goverse G, Vinuesa CG, Mebius RE, et al. Dietary fiber and bacterial SCFA enhance oral tolerance and protect against food allergy through diverse cellular pathways. Cell Rep. (2016) 15:2809-24. doi: 10.1016/j.celrep.2016.05.047

45. Maslowski KM, Vieira AT, Ng A, Kranich J, Sierro F, Di Yu MacKay CR. Regulation of inflammatory responses by gut microbiota 
and chemoattractant receptor GPR43. Nature. (2009) 461:1282-6. doi: $10.1038 /$ nature 08530

46. Berni Canani R, Di Costanzo M, Leone L. The epigenetic effects of butyrate: potential therapeutic implications for clinical practice. Clin Epigenetics. (2012) 4:4. doi: 10.1186/1868-7083-4-4

47. Canani RB, Costanzo MD, Leone L, Pedata M, Meli R, Calignano A. Potential beneficial effects of butyrate in intestinal and extraintestinal diseases. World J Gastroenterol. (2011) 17:1519-28. doi: 10.3748/wjg.v17.i12.1519

48. Rudloff S, Kunz C. The glycobiology of human milk oligosaccharides - milk oligosaccharides and metabolism in infants. Adv Nutr. (2012) 3:398S-405S. doi: 10.3945/an.111.001594

49. Gnoth MJ, Rudloff S, Kunz C, Kinne RKH. Investigations of the in vitro transport of human milk oligosaccharides by a caco-2 monolayer using a novel high performance liquid chromatography-mass spectrometry technique. J Biol Chem. (2001) 276:34363-70. doi: 10.1074/jbc.M1048 05200

50. Bode L, Kunz C, Muhly-Reinholz M, Mayer K, Seeger W, Rudloff S. Inhibition of monocyte, lymphocyte, and neutrophil adhesion to endothelial cells by human milk oligosaccharides. Thromb Haemost. (2004) 92:1402-10. doi: 10.1160/TH04-01-0055

51. Atochina, O, Harn D. LNFPIII/LeX-stimulated macrophages activate natural killer cells via CD40-CD40L interaction. Clin Diagn Lab Immunol. (2005) 12:1041-9. doi: 10.1128/CDLI.12.9.1041-1049.2005

52. Terrazas LI, Walsh KL, Piskorska D, McGuire E, Harn DA. The schistosome oligosaccharide lacto- $\mathrm{N}$-neotetraose expands Gr1 + cells that secrete antiinflammatory cytokines and inhibit proliferation of naive $\mathrm{CD} 4+$ cells: a potential mechanism for immune polarization in helminth infections. $J$ Immunol. (2001) 167:5294-303. doi: 10.4049/jimmunol.167.9.5294

53. Eiwegger T, Stahl B, Schmitt J, Boehm G, Gerstmayr M, Pichler J, et al. Human milk-derived oligosaccharides and plant-derived oligosaccharides stimulate cytokine production of cord blood T-cells in vitro. Pediatr Res. (2004) 56:536-40. doi: 10.1203/01.PDR.0000139411.35619.B4

54. Triantis V, Bode L, van Neerven JRJ. Immunological effects of human milk oligosaccharides. Front Pediatrics. (2018) 6:190. doi: 10.3389/fped.2018.00190

55. Chirico G, Marzollo R, Cortinovis S, Fonte C, Gasparoni A. Antiinfective properties of human milk. J Nutr. (2008) 138:1801S-6S. doi: 10.1093/jn/138.9.1801S

56. Dawod B, Marshall JS. Cytokines and soluble receptors in breast milk as enhancers of oral tolerance development. Front Immunol. (2019) 10:16. doi: 10.3389/fimmu.2019.00016

57. Agarwal S, Karmaus W, Davis S, Gangur V. Immune markers in breast milk and fetal and maternal body fluids: A systematic review of perinatal concentrations. J Hum Lactation. (2011) 27:171-86. doi: $10.1177 / 0890334410395761$

58. Ciardelli L, Garofoli F, Stronati M, Mazzucchelli I, Avanzini MA, Figar T, et al. Human colostrum lymphocytes aid their effector cytokines actively aid and the development of the newborn immune system. Int J Immunopathol Pharmacol. (2008) 21:781-6. doi: 10.1177/039463200802100402

59. Arend WP. The balance between IL-1 and IL-1Ra in disease. Cytokine Growth Factor Rev. (2002) 13:323-40. doi: 10.1016/S1359-6101(02)00020-5

60. Minekawa R, Takeda T, Sakata M, Hayashi M, Isobe A, Yamamoto T, et al. Human breast milk suppresses the transcriptional regulation of IL$1 \beta$-induced NF- $\mathrm{KB}$ signaling in human intestinal cells. Am J Physiol. (2004) 287:C1404-11. doi: 10.1152/ajpcell.00471.2003

61. Liu T, Zhang L, Joo D, Sun SC. NF-кB signaling in inflammation. Signal Transduct Targeted Ther. (2017) 2:17023. doi: 10.1038/sigtrans.2017.23

62. Nolan LS, Parks OB, Good M. A review of the immunomodulating components of maternal breast milk and protection against necrotizing enterocolitis. Nutrients. (2020) 12. doi: 10.3390/nu12010014

63. Hui L, Dai Y, Guo Z, Zhang J, Zheng F, Bian X, et al. Immunoregulation effects of different $\gamma \delta \mathrm{T}$ cells and toll-like receptor signaling pathways in neonatal necrotizing enterocolitis. Medicine. (2017) 96:e6077. doi: 10.1097/MD.0000000000006077

64. Yu JC, Khodadadi H, Malik A, Davidson B, Salles É, da SL, et al. Innate immunity of neonates and infants. Front Immunol. (2018) 9:1759. doi: 10.3389/fimmu.2018.01759
65. Maheshwari A, Lu W, Lacson A, Barleycorn AA, Nolan S, Christensen RD, et al. Effects of interleukin-8 on the developing human intestine. Cytokine. (2002) 20:256-67. doi: 10.1006/cyto.2002.1996

66. Gila-Diaz A, Arribas SM, Algara A, Martín-Cabrejas MA, Pablo ÁLL, de, et al. A review of bioactive factors in human breastmilk: A focus on prematurity. Nutrients. (2019) 11:1307. doi: 10.3390/nu110 61307

67. Bradford EM, Ryu SH, Singh AP, Lee G, Goretsky T, Sinh P, et al. Epithelial TNF receptor signaling promotes mucosal repair in inflammatory bowel disease. J Immunol. (2017) 199:1886-97. doi: 10.4049/jimmunol. 1601066

68. Ando T, Hatsushika K, Wako M, Ohba T, Koyama K, Ohnuma Y, et al. Orally administered TGF- $\beta$ is biologically active in the intestinal mucosa and enhances oral tolerance. J Allergy Clin Immunol. (2007) 120:916-23. doi: 10.1016/j.jaci.2007.05.023

69. Melnik BC, John SM, Carrera-Bastos P, Schmitz G. Milk: A postnatal imprinting system stabilizing FoxP3 expression and regulatory $\mathrm{T}$ cell differentiation. Clin Translational Allergy. (2016) 6:18. doi: 10.1186/s13601-016-0108-9

70. Sitarik AR, Bobbitt KR, Havstad SL, Fujimura KE, Levin AM, Zoratti EM, et al. Breast milk transforming growth factor $\beta$ is associated with neonatal gut microbial composition. J Pediatr Gastroenterol Nutr. (2017) 65:e60-7. doi: 10.1097/MPG.0000000000001585

71. Ogawa J, Sasahara A, Yoshida T, Sira M. M., Futatani T, Kanegane H, et al. Role of transforming growth factor- $\beta$ in breast milk for initiation of IgA production in newborn infants. Early Hum Dev. (2004) 77:67-75. doi: 10.1016/j.earlhumdev.2004.01.005

72. Shiou SR, Yu Y, Guo Y, Westerhoff M, Lu L, Petrof EO, et al. Oral administration of transforming growth Factor- $\beta 1$ (TGF- $\beta 1$ ) protects the immature gut from injury via smad proteindependent suppression of epithelial nuclear factor $\kappa \mathrm{b}(\mathrm{NF}-\kappa \mathrm{B})$ signaling and proinflammatory cytokine production. J Biol Chem. (2013) 288:34757-66. doi: 10.1074/jbc.M113.503946

73. Rautava S, Lu L, Nanthakumar NN, Dubert-Ferrandon A, Walker WA. TGF- $\beta 2$ induces maturation of immature human intestinal epithelial cells and inhibits inflammatory cytokine responses induced via the NF-кB pathway. J Pediatr Gastroenterol Nutr. (2012) 54:630-8. doi: 10.1097/MPG.0b013e31823e7c29

74. Morita Y, Campos-Alberto E, Yamaide F, Nakano T, Ohnisi H, Kawamoto M, et al. TGF- $\beta$ concentration in breast milk is associated with the development of eczema in infants. Front Pediatrics. (2018) 6:162. doi: 10.3389/fped.2018. 00162

75. Coursodon CF, Dvorak B. Epidermal growth factor and necrotizing enterocolitis. Curr Opin Pediatr. (2012) 24:160-4. doi: 10.1097/MOP.0b013e3283504ddb

76. Nair RR, Warner BB, Warner BW. Role of epidermal growth factor and other growth factors in the prevention of necrotizing enterocolitis. Semin Perinatol. (2008) 315:G259-71. doi: 10.1053/j.semperi.2008. 01.007

77. Halpern MD, Holubec H, Dominguez JA, Williams CS, Meza YG, McWilliam DL, et al. Up-regulation of IL-18 and IL-12 in the ileum of neonatal rats with necrotizing enterocolitis. Pediatr Res. (2002) 51:733-9. doi: 10.1203/00006450-200206000-00012

78. Vass RA, Kemeny A, Dergez T, Ertl T, Reglodi D, Jungling A, et al. Distribution of bioactive factors in human milk samples. Int Breastfeed J. (2019) 14. doi: 10.1186/s13006-019-0203-3

79. Ballard O, Morrow AL. Human milk composition. Nutr Bioactive Factors. (2013) 156:S36-40. doi: 10.1016/j.pcl.2012.10.002

80. Dvorak B. Milk epidermal growth factor and gut protection. J Pediatrics. (2010) 156(2 sUppl):S31-S35. doi: 10.1016/j.jpeds.2009.11.018

81. Rocourt DV, Mehta VB, Besner GE. Heparin-Binding EGF-like growth factor decreases inflammatory cytokine expression after intestinal ischemia/reperfusion injury. J Surg Res. (2007) 139:269-73. doi: 10.1016/j.jss.2006.10.047

82. Dvorak B, Ludmila K, Clark JA, Hosseini DM, Arganbright KM, Reynolds CA, Halpern MD. Comparison of epidermal growth factor and heparinbinding epidermal growth factor-like growth factor for prevention of 
experimental necrotizing enterocolitis. J Pediatr Gastroenterol Nutr. (2008) 47:11-8. doi: 10.1097/MPG.0b013e3181788618

83. Ozgurtas T, Aydin I, Turan O, Koc E, Hirfanoglu IM, Acikel CH, et al. Vascular endothelial growth factor, basic fibroblast growth factor, insulinlike growth factor-I and platelet-derived growth factor levels in human milk of mothers with term and preterm neonates. Cytokine. (2010) 50:192-4. doi: 10.1016/j.cyto.2010.02.008

84. Karatepe HO, Kilincaslan H, Berber M, Ozen A, Saricoban HE, Ustek D, et al. The effect of vascular endothelial growth factor overexpression in experimental necrotizing enterocolitis. Pediatr Surg Int. (2014) 30:327-32. doi: $10.1007 / \mathrm{s} 00383-013-3460-\mathrm{z}$

85. Palmeira P, Carneiro-Sampaio M. Immunology of breast milk. Revista Associacao Med Brasileira. (2016) 62:584-93. doi: 10.1590/1806-9282.62.06.584

86. Gottrand F. Long-chain polyunsaturated fatty acids influence the immune system of infants. J Nutrition. (2008) 138:1807S-12S. doi: $10.1093 /$ jn/138.9.1807S

87. Berod L, Friedrich C, Nandan A, Freitag J, Hagemann S, Harmrolfs K, et al. De novo fatty acid synthesis controls the fate between regulatory $\mathrm{T}$ and $\mathrm{T}$ helper 17 cells. Nat Med. (2014) 20:1327-33. doi: 10.1038/nm.3704

88. Calder PC. Omega-3 fatty acids and inflammatory processes. Nutrients. (2010) 2:355-74. doi: 10.3390/nu2030355

89. Lu J, Jilling T, Li D, Caplan MS. Polyunsaturated fatty acid supplementation alters proinflammatory gene expression and reduces the incidence of necrotizing enterocolitis in a neonatal rat model. Pediatr Res. (2007) 61:42732. doi: 10.1203/pdr.0b013e3180332ca5

90. Caplan MS, Russell T, Xiao Y, Amer M, Kaup S, Jilling T. Effect of polyunsaturated fatty acid (PUFA) supplementation on intestinal inflammation and necrotizing enterocolitis (NEC) in a neonatal rat model. Pediatr Res. (2001) 49:647-52. doi: 10.1203/00006450-200105000-00007

91. Serhan CN, Clish CB, Brannon J, Colgan SP, Chiang N, Gronert K. Novel functional sets of lipid-derived mediators with antiinflammatory actions generated from omega-3 fatty acids via cyclooxygenase 2-nonsteroidal antiinflammatory drugs and transcellular processing. J Exp Med. (2000) 192:1197-204. doi: 10.1084/jem.192.8.1197

92. Quin C, Gibson DL. Dietary fatty acids and host-microbial crosstalk in neonatal enteric infection. Nutrients. (2019) 11:2064. doi: 10.3390/nu11092064

93. Ghosh S, DeCoffe D, Brown K, Rajendiran E, Estaki M, Dai C, et al. Fish oil attenuates omega- 6 polyunsaturated fatty acid-induced dysbiosis and infectious colitis but Impairs LPS dephosphorylation activity causing sepsis. PLoS ONE. (2013) 8:e55468. doi: 10.1371/journal.pone.0055468

94. Calder PC. n-3 Polyunsaturated fatty acids, inflammation, inflammatory diseases. Am J Clin Nutr. (2006) 83:1505S-19S. doi: 10.1093/ajcn/83.6.1505S

95. Contarini G, Povolo M. Phospholipids in milk fat: composition, biological and technological significance, and analytical strategies. Int J Mol Sci. (2013) 14:2808-31. doi: 10.3390/ijms14022808

96. Cilla A, Diego Quintaes K, Barberá R, Alegría A. Phospholipids in human milk and infant formulas: benefits and needs for correct infant nutrition. Crit Rev Food Sci Nutr. (2016) 56:1880-92. doi: 10.1080/10408398.2013.803951

97. Parodi PW. Milk fat in human nutrition. Australian J Dairy Technol. (2004) 59:3-59.

98. Koletzko B. Human milk lipids. Annals Nutrition Metabolism. (2017) 69:2840. doi: 10.1159/000452819

99. Isaacs CE. The antimicrobial function of milk lipids. Adv Nutr Res. (2001) 10:271-85. doi: 10.1007/978-1-4615-0661-4_13

100. Pfaender S, Heyden J, Friesland M, Ciesek S, Ejaz A, Steinmann J, et al. Inactivation of hepatitis $\mathrm{C}$ virus infectivity by human breast milk. J Infect Dis. (2013) 208:1943-52. doi: 10.1093/infdis/jit519

101. Jhaveri R. Protection against hepatitis C and other enveloped viruses? Another reason why "breast is best". J Infect Dis. (2013) 208:1932-3. doi: 10.1093/infdis/jit521

102. Civra A, Leoni V, Caccia C, Sottemano S, Tonetto P, Coscia A, et al. Antiviral oxysterols are present in human milk at diverse stages of lactation. J Steroid Biochem Mol Biol. (2019) 193. doi: 10.1016/j.jsbmb.2019.105424

103. Lembo D, Cagno V, Civra A, Poli G. Oxysterols: An emerging class of broad spectrum antiviral effectors. Mol Aspects Med. (2016) 49:23-30. doi: 10.1016/j.mam.2016.04.003
104. Lönnerdal B. Bioactive proteins in human milk: mechanisms of action. J Pediatrics. (2010) 156(2 Suppl):S26-30. doi: 10.1016/j.jpeds.2009.11.017

105. Zhu J, Dingess KA. The functional power of the human milk proteome. Nutrients. (2019) 11:1834. doi: 10.3390/nu11081834

106. Lönnerdal B. Human milk: bioactive proteins/peptides and functional properties. Nestle Nutr Inst Workshop Ser. (2016) 86:97-107. doi: 10.1159/000442729

107. Ahmed A, Siman-Tov G, Hall G, Bhalla N, Narayanan A. Human antimicrobial peptides as therapeutics for viral infections. Viruses. (2019) 11:704. doi: 10.3390/v11080704

108. Hurley WL, Theil PK. Perspectives on immunoglobulins in colostrum and milk. Nutrients. (2011) 3:442-74. doi: 10.3390/nu3040442

109. Lepage P, Van De Perre P. The immune system of breast milk: antimicrobial and anti-inflammatory properties. Adv Exp Med Biol. (2012) 743:121-37. doi: 10.1007/978-1-4614-2251-8_9

110. Brandtzaeg P. The mucosal immune system and its integration with the mammary glands. J Pediatrics. (2010) 156:S8. doi: 10.1016/j.jpeds.2009.11.014

111. Rogier EW, Frantz AL, Bruno MEC, Kaetzel CS. Secretory IgA is concentrated in the outer layer of colonic mucus along with gut bacteria. Pathogens. (2014) 3:390-403. doi: 10.3390/pathogens3020390

112. Gopalakrishna KP, Macadangdang BR, Rogers MB, Tometich JT, Firek $\mathrm{BA}$, Baker $\mathrm{R}$, et al. Maternal IgA protects against the development of necrotizing enterocolitis in preterm infants. Nat Med. (2019) 25:1110-5. doi: 10.1038/s41591-019-0480-9

113. Johansen FE, Brandtzaeg P. Transcriptional regulation of the mucosal IgA system. Trends Immunol. (2004) 25:150-7. doi: 10.1016/j.it.2004.01.001

114. Edmond K, Zaidi A. New approaches to preventing, diagnosing, and treating neonatal sepsis. PLoS Med. (2010) 7:e1000213. doi: 10.1371/journal.pmed.1000213

115. Andreas NJ, Kampmann B, Mehring Le-Doare K. Human breast milk: a review on its composition and bioactivity. Early Hum Dev. (2015) 91:629-35. doi: 10.1016/j.earlhumdev.2015.08.013

116. Kanwar J, Kanwar R, Sun X, Punj V, Matta H, Morley S, et al. Molecular and biotechnological advances in milk proteins in relation to human health. Curr Protein Pept Sci. (2009) 10:308-38. doi: 10.2174/138920309788922234

117. Berlutti F, Pantanella F, Natalizi T, Frioni A, Paesano R, Polimeni A, et al. Antiviral properties of lactoferrin $\backslash$-a natural immunity molecule. Molecules. (2011) 16:6992-7012. doi: 10.3390/molecules 16086992

118. Elass E, Masson M, Mazurier J, Legrand D. Lactoferrin inhibits the lipopolysaccharide-induced expression and proteoglycan-binding ability of interleukin-8 in human endothelial cells. Infect Immun. (2002) 70:1860-6. doi: 10.1128/IAI.70.4.1860-1866.2002

119. Håversen LA, Baltzer L, Dolphin G, Hanson LÅ, Mattsby-Baltzer I. Anti-Inflammatory Activities of Human Lactoferrin in Acute Dextran Sulphate-Induced Colitis in Mice. Scand J Immunol. (2003) 57:2-10. doi: 10.1046/j.1365-3083.2003.01162.x

120. Zemankova N, Chlebova K, Matiasovic J, Prodelalova J, Gebauer J, Faldyna M. Bovine lactoferrin free of lipopolysaccharide can induce a proinflammatory response of macrophages. BMC Vet. Res. (2016) 12(1): doi: 10.1186/s12917-016-0878-2

121. Ochoa TJ, Brown EL, Guion CE, Chen JZ, McMahon RJ, Cleary TG. Effect of lactoferrin on enteroaggregative E. coli (EAEC). Biochem Cell Biol. (2006) 84:369-76. doi: 10.1139/o06-053

122. Telang S. Lactoferrin: A critical player in neonatal host defense. Nutrients. (2018) 10:1228. doi: 10.3390/nu10091228

123. Ward PP, Paz E, Conneely OM. Multifunctional roles of lactoferrin: a critical overview. Cell Mol Life Sci. (2005) 62:2540. doi: 10.1007/s00018-005-5369-8

124. Wakabayashi H, Oda H, Yamauchi K, Abe F. Lactoferrin for prevention of common viral infections. J Infect Chemother. (2014) 20:666-71. doi: 10.1016/j.jiac.2014.08.003

125. Groot, F, Geijtenbeek, TB, Sanders, RW, et al. Lactoferrin prevents dendritic cell-mediated human immunodeficiency virus type 1 transmission by blocking the DC-SIGN-gp120 interaction. J Virol. (2005) 79:3009-15. doi: 10.1128/JVI.79.5.3009-3015.2005

126. González-Chávez SA, Arévalo-Gallegos S, Rascón-Cruz Q. Lactoferrin: structure, function and applications. Int J Antimicrobial Agents. (2009) 33:301.e1-8. doi: 10.1016/j.ijantimicag.2008.07.020 
127. Legrand D. Overview of lactoferrin as a natural immune modulator. $J$ Pediatrics. (2016) 173:S10-5. doi: 10.1016/j.jpeds.2016.02.071

128. Andonegui G, Zhou H, Bullard D, Kelly MM, Mullaly SC, McDonald B, et al. Mice that exclusively express TLR4 on endothelial cells can efficiently clear a lethal systemic Gram-negative bacterial infection. J Clin Investigation. (2009) 119:1921-30. doi: 10.1172/JCI36411

129. Raoof NA, Adamkin DH, Radmacher PG, Telang S. Comparison of lactoferrin activity in fresh and stored human milk. J Perinatol. (2016) 36:207-9. doi: 10.1038/jp.2015.186

130. Tanida T, Rao F, Hamada T, Ueta E, Osaki T. Lactoferrin peptide increases the survival of Candida albicans - Inoculated mice by upregulating neutrophil and macrophage functions, especially in combination with amphotericin $\mathrm{B}$ and granulocyte-macrophage colony-stimulating factor. Infect Immun. (2001) 69:3883-90. doi: 10.1128/IAI.69.6.3883-3890.2001

131. Kai K, Komine K. I., Komine Y, Kuroishi T, Kozutsumi T, Kobayashi J, et al. Lactoferrin stimulates a Staphylococcus aureus killing activity of bovine phagocytes in the mammary gland. Microbiol Immunol. (2002) 46:187-94. doi: $10.1111 /$ j.1348-0421.2002.tb02685.x

132. Actor J, Hwang, SA, Kruzel M. Lactoferrin as a natural immune modulator. Curr Pharm Des. (2009) 15:1956-73. doi: $10.2174 / 138161209788453202$

133. Trinchieri G. Interleukin-12 and the regulation of innate resistance and adaptive immunity. Nat Rev Immunol. (2003) 3:133-46. doi: 10.1038/nri1001

134. Spadaro M, Caorsi C, Ceruti P, Varadhachary A, Forni G, Pericle F, et al. Lactoferrin, a major defense protein of innate immunity, is a novel maturation factor for human dendritic cells. FASEB J. (2008) 22:2747-57. doi: 10.1096/fj.07-098038

135. Artym J, Zimecki M, Kruzel ML. Reconstitution of the cellular immune response by lactoferrin in cyclophosphamide-treated mice is correlated with renewal of T cell compartment. Immunobiology. (2003) 207:197-205. doi: 10.1078/0171-2985-00233

136. Claud EC, Walker WA. Hypothesis: inappropriate colonization of the premature intestine can cause neonatal necrotizing enterocolitis. FASEB J. (2001) 15:1398-403. doi: 10.1096/fj.00-0833hyp

137. Manzoni P. Clinical benefits of lactoferrin for infants and children. $J$ Pediatrics. (2016) 173:S43-52. doi: 10.1016/j.jpeds.2016.02.075

138. Cacho NT, Lawrence RM. Innate immunity and breast milk. Front Immunol. (2017) 8:584. doi: 10.3389/fimmu.2017.00584

139. Zwirzitz A, Reiter M, Skrabana R, Ohradanova-Repic A, Majdic O, Gutekova $\mathrm{M}$, et al. Lactoferrin is a natural inhibitor of plasminogen activation. J Biol Chem. (2018) 293:8600-13. doi: 10.1074/jbc.RA118.003145

140. Bournazou I, Pound JD, Duffin R, Bournazos S, Melville LA, Brown SB, et al. Apoptotic human cells inhibit migration of granulocytes via release of lactoferrin. J Clin Investigation. (2009) 119:20-32. doi: 10.1172/JCI36226

141. Bremme KA. Haemostatic changes in pregnancy. Best Pract Res. (2003) 16:153-68. doi: 10.1016/S1521-6926(03)00021-5

142. Brenner B. Haemostatic changes in pregnancy. Thrombosis Res. (2004) 114:409-14. doi: 10.1016/j.thromres.2004.08.004

143. Liu J, Li J, Arnold K, Pawlinski R, Key NS. Using heparin molecules to manage COVID-2019. Res Pract Thrombosis Haemostasis. (2020) 4:518-23. doi: $10.1002 / \mathrm{rth} 2.12353$

144. Wang X, Zhou Z, Zhang J, Zhu F, Tang Y, Shen X. A case of 2019 novel coronavirus in a pregnant woman with preterm delivery. Clin Infect Dis. (2020) 71:844-6. doi: 10.1093/cid/ciaa200

145. Campione E, Cosio T, Rosa L, Lanna C, Girolamo SD, Gaziano R, et al. Lactoferrin as protective natural barrier of respiratory and intestinal mucosa against coronavirus infection and inflammation. Int J Mol Sci. (2020) 21:4903. doi: 10.3390/ijms21144903

146. Kusunoki R, Ishihara S, Aziz M, Oka A, Tada Y, Kinoshita Y. Roles of milk fat globule-epidermal growth factor 8 in intestinal inflammation. Digestion. (2012) 85:103-7. doi: 10.1159/000334679

147. Chogle A, Bu HF, Wang X, Brown JB, Chou PM, Tan XD. Milk fat globule-EGF factor 8 is a critical protein for healing of dextran sodium sulfate-induced acute colitis in mice. Mol Med. (2011) 17:502-7. doi: 10.2119/molmed.2010.00074

148. Garcia C, Duan RD, Brévaut-Malaty V, Gire C, Millet V, Simeoni U, et al. Bioactive compounds in human milk and intestinal health and maturity in preterm newborn: an overview. Cell Mol Biol. (2013) 59:108-31.
149. Aziz M, Jacob A, Matsuda A, Wang P. Review: milk fat globule-EGF factor 8 expression, function and plausible signal transduction in resolving inflammation. Apoptosis. (2011) 16:1077-86. doi: 10.1007/s10495-0110630-0

150. Cheyuo C, Jacob A, Wu R, Zhou M, Qi L, Dong W, et al. Recombinant human MFG-E8 attenuates cerebral ischemic injury: its role in antiinflammation and anti-apoptosis. Neuropharmacology. (2012) 62:890-900. doi: 10.1016/j.neuropharm.2011.09.018

151. Dasgupta SK, Abdel-Monem H, Niravath P, Le A, Bellera RV, Langlois K, et al. Lactadherin and clearance of platelet-derived microvesicles. Blood. (2009) 113:1332-9. doi: 10.1182/blood-2008-07-167148

152. Newburg DS. Neonatal protection by an innate immune system of human milk consisting of oligosaccharides and glycans. J Anim Sci. (2009) 87:26-34. doi: $10.2527 /$ jas.2008-1347

153. Yang D, Chertov O, Oppenheim JJ. The role of mammalian antimicrobial peptides and proteins in awakening of innate host defenses and adaptive immunity. Cel Mol Life Sci. (2001) 58:978-89. doi: 10.1007/PL00000914

154. Baricelli J, Rocafull MA, Vázquez D, Bastidas B, Báez-Ramirez E, Thomas LE. $\beta$-defensin-2 in breast milk displays a broad antimicrobial activity against pathogenic bacteria. J Pediatr. (2015) 91:36-43. doi: 10.1016/j.jped.2014.05.006

155. Jenke ACW, Zilbauer M, Postberg J, Wirth S. Human $\beta$-defensin 2 expression in ELBW infants with severe necrotizing enterocolitis. Pediatr Res. (2012) 72:513-20. doi: 10.1038/pr.2012.110

156. Diebold SS, Kaisho T, Hemmi H, Akira S, Reis E Sousa C. Innate antiviral responses by means of TLR7-mediated recognition of single-stranded RNA. Science. (2004) 303:1529-31. doi: 10.1126/science.1093616

157. Stroinigg N, Srivastava MD. Modulation of toll-like receptor 7 and LL-37 expression in colon and breast epithelial cells by human $\beta$-defensin-2. Allergy Asthma Proc. (2005) 26:299-309.

158. Salzman NH, Underwood MA, Bevins CL. Paneth cells, defensins, and the commensal microbiota: a hypothesis on intimate interplay at the intestinal mucosa. Semin Immunol. (2007) 19:70-83. doi: 10.1016/j.smim.2007.04.002

159. Kaur S, Kaur Panaich M, Kaur Virk S, Choudhary M, Sharma C, Chauhan $S$, et al. Prophylactic and therapeutic role of human breast milk proteins and bioactive peptides against neonatal bacterial infections. Infant Feeding. (2020). doi: 10.5772/intechopen.91865

160. Nagatomo T, Ohga S, Takada H, Nomura A, Hikino S, Imura M, et al. Microarray analysis of human milk cells: Persistent high expression of osteopontin during the lactation period. Clin Exp Immunol. (2004) 138:4753. doi: 10.1111/j.1365-2249.2004.02549.x

161. Wang KX, Denhardt DT. Osteopontin: role in immune regulation and stress responses. Cytokine Growth Factor Rev. (2008) 19:333-45. doi: 10.1016/j.cytogfr.2008.08.001

162. Azuma N, Maeta A, Fukuchi K, Kanno C. A rapid method for purifying osteopontin from bovine milk and interaction between osteopontin and other milk proteins. Int Dairy J. (2006) 16:370-8. doi: 10.1016/j.idairyj.2005.03.012

163. Lonnerdal B, Kvistgaard AS, Peerson JM, Donovan SM, Peng YM. Growth nutrition, and cytokine response of breast-fed infants and infants fed formula with added bovine osteopontin. J Pediatr Gastroenterol Nutr. (2015) 62:6507. doi: 10.1097/MPG.0000000000001005

164. Ozsurekci Y, Aykac K. Oxidative stress related diseases in newborns. Oxidative Med Cell Longevity. (2016) 2016:2768365. doi: $10.1155 / 2016 / 2768365$

165. Shoji H, Koletzko B. Oxidative stress and antioxidant protection in the perinatal period. Curr Opin Clin Nutr Metab Care. (2007) 10:324-8. doi: 10.1097/MCO.0b013e3280a94f6d

166. Mehta R, Petrova A. Is variation in total antioxidant capacity of human milk associated with levels of bio-active proteins? J Perinatol. (2014) 34:220-2. doi: 10.1038/jp.2013.151

167. Park M, Youn BS, Zheng X, long, Wu D, Xu A, et al. Globular adiponectin, acting via AdipoR1/APPL1, protects $\mathrm{H} 9 \mathrm{c} 2$ cells from hypoxia/reoxygenation-induced apoptosis. PLoS ONE. (2011) 6:e19143. doi: 10.1371/journal.pone.0019143

168. Liu H, Zheng F, Cao Q, Ren B, Zhu L, Striker G, et al. Amelioration of oxidant stress by the defensin lysozyme. Am J Physiol. (2006) 290:E824-32. doi: 10.1152/ajpendo.00349.2005 
169. Bonnefont-Rousselot D, Collin F. Melatonin: action as antioxidant and potential applications in human disease and aging. Toxicology. (2010) 278:55-67. doi: 10.1016/j.tox.2010.04.008

170. O’Rourke L, Clarke G, Nolan A, Watkins C, Dinan TG, Stanton C, et al. Tryptophan metabolic profile in term and preterm breast milk: implications for health. J Nutr Sci. (2018) 7:e13. doi: 10.1017/jns.2017.69

171. Lozano B, Castellote AI, Montes R, López-Sabater MC. Vitamins, fatty acids, and antioxidant capacity stability during storage of freeze-dried human milk. Int J Food Sci Nutr. (2014) 65:703-7. doi: 10.3109/09637486.2014.917154

172. Ichikawa M, Sugita M, Takahashi M, Satomi M, Takeshita T, Araki T, et al. Breast milk macrophages spontaneously produce granulocyte-macrophage colony-stimulating factor and differentiate into dendritic cells in the presence of exogenous interleukin-4 alone. Immunology. (2003) 108:189-95. doi: 10.1046/j.1365-2567.2003.01572.x

173. Indumathi S, Dhanasekaran M, Rajkumar JS, Sudarsanam D. Exploring the stem cell and non-stem cell constituents of human breast milk. Cytotechnology. (2013) 65:385-93. doi: 10.1007/s10616-012-9492-8

174. Sabbaj S, Ibegbu CC, Kourtis AP. Cellular immunity in breast milk: implications for postnatal transmission of HIV-1 to the infant. Adv Exp Med Biol. (2012) 743:161-9. doi: 10.1007/978-1-4614-2251-8_11

175. Yagi Y, Watanabe E, Watari E, Shinya E, Satomi M, Takeshita T, et al. Inhibition of DC-SIGN-mediated transmission of human immunodeficiency virus type 1 by Toll-like receptor 3 signalling in breast milk macrophages. Immunology. (2010) 130:597-607. doi: 10.1111/j.1365-2567.2010.03264.x

176. Landgraf P, Rusu M, Sheridan R, Sewer A, Iovino N, Aravin A, et al. A mammalian microRNA Expression Atlas Based on Small RNA Library Sequencing. Cell. (2007) 129:1401-14. doi: 10.1016/j.cell.2007.04.040

177. Weber JA, Baxter DH, Zhang S, Huang DY, Huang KH, Lee MJ, et al. The microRNA spectrum in 12 body fluids. Clin Chem. (2010) 56:1733-41. doi: $10.1373 /$ clinchem.2010.147405

178. He L, Hannon GJ. MicroRNAs: Small RNAs with a big role in gene regulation. Nat Rev Genetics. (2004) 5:522-31. doi: 10.1038/nrg1379

179. Pritchard CC, Cheng HH, Tewari M. Micro RNA profiling: approaches and considerations. Nat Rev Genet. (2012) 13:358-69. doi: 10.1038/nrg3198

180. Ninkina N, Kukharsky MS, Hewitt MV, Lysikova EA, Skuratovska LN, Deykin AV, et al. Stem cells in human breast milk. Human Cell. (2019) 32:223-30. doi: 10.1007/s13577-019-00251-7

181. Wang T, Du Z, Zhu F, Cao Z, An Y, Gao Y, et al. Comorbidities and multi-organ injuries in the treatment of COVID-19. Lancet. (2020) 395:e52. doi: 10.1016/S0140-6736(20)30558-4

182. Escher R, Breakey N, Lämmle B. Severe COVID-19 infection associated with endothelial activation. Thrombosis Res. (2020) 190:62. doi: 10.1016/j.thromres.2020.04.014

183. Pandolfi E, Gesualdo F, Rizzo C, Carloni E, Villani A, Concato C, et al. Breastfeeding and respiratory infections in the first 6 months of life: A case control study. Front Pediatrics. (2019) 7:152. doi: 10.3389/fped.2019.00152

184. Dixon DL, Griggs KM, Forsyth KD, Bersten AD. Lower interleukin8 levels in airway aspirates from breastfed infants with acute bronchiolitis. Pediatric Allergy Immunol. (2010) 21:e691-e696. doi: 10.1111/j.1399-3038.2010.01011.x

185. Nishimura T, Suzue J, Kaji H. Breastfeeding reduces the severity of respiratory syncytial virus infection among young infants: a multi-center prospective study. Pediatrics Int. (2009) 51:812-6. doi: 10.1111/j.1442-200X.2009.02877.x

186. Mulligan P, White NRJ, Monteleone G, Wang P, Wilson JW, Ohtsuka Y, et al. Breast milk lactoferrin regulates gene expression by binding bacterial DNA CpG motifs but not genomic DNA promoters in model intestinal cells. Pediatr Res. (2006) 59:656-61. doi: 10.1203/01.pdr.0000214958. 80011.e1

187. Bode L. The functional biology of human milk oligosaccharides. Early Hum Dev. (2015) 91:619-22.. doi: 10.1016/j.earlhumdev.2015.09.001

188. Bryan DL, Hart PH, Forsyth KD, Gibson RA. Immunomodulatory constituents of human milk change in response to infant bronchiolitis. Pediatric Allergy Immunol. (2007) 18:495-502. doi: 10.1111/j.1399-3038.2007.00565.x

189. Jang MJ, Kim YJ, Hong S, Na J, Hwang JH, Shin SM, et al. Positive association of breastfeeding on respiratory syncytial virus infection in hospitalized infants: a multicenter retrospective study. Korean J Pediatr. (2020) 63:13540. doi: 10.3345/kjp.2019.00402

190. Van der Strate BWA, Beljaars L, Molema G, Harmsen MC, Meijer DKF. Antiviral activities of lactoferrin. Antiviral Res. (2001 52:225-39. doi: 10.1016/S0166-3542(01)00195-4

191. Henrick BM, Nag K, Yao XD, Drannik AG, Aldrovandi GM, Rosenthal KL. Milk matters: Soluble toll-like receptor 2 (sTLR2) in breast milk significantly inhibits HIV-1 infection and inflammation. PLoS ONE. (2012) 7:e40138. doi: 10.1371/journal.pone.0040138

192. Huang P, Farkas T, Zhong W, Tan M, Thornton S, Morrow AL, et al. Norovirus and histo-blood group antigens: demonstration of a wide spectrum of strain specificities and classification of two major binding groups among multiple binding patterns. J Virol. (2005) 79:6714-22. doi: 10.1128/JVI.79.11.6714-6722.2005

193. Weichert S, Koromyslova A, Singh BK, Hansman S, Jennewein S, Schroten $\mathrm{H}$, et al. Structural basis for norovirus inhibition by human milk oligosaccharides. J Virol. (2016) 90:4843-8. doi: 10.1128/JVI. 03223-15

194. Brandtzaeg P. The gut as communicator between environment and host: immunological consequences. Eur J Pharmacol. (2011) 668:S16-S32. doi: 10.1016/j.ejphar.2011.07.006

195. Parashar UD, Nelson EAS, Kang G. Diagnosis, management, and prevention of rotavirus gastroenteritis in children. BMJ. (2013) 347:f7204. doi: 10.1136/bmj.f7204

196. Krawczyk A, Lewis MG, Venkatesh BT, Nair SN. Effect of Exclusive Breastfeeding on Rotavirus Infection among Children. Indian J Pediatr. (2016) 83:220-5. doi: 10.1007/s12098-015-1854-8

197. Saadeh MR. A new global strategy for infant and young child feeding. Forum Nutr. (2003) 56:236-8.

198. Ramani S, Stewart CJ, Laucirica DR, Ajami NJ, Robertson B, Autran $\mathrm{CA}$, et al. Human milk oligosaccharides, milk microbiome and infant gut microbiome modulate neonatal rotavirus infection. Nat Commun. (2018) 9:5010. doi: 10.1038/s41467-018-07476-4

199. Koromyslova A, Tripathi S, Morozov V, Schroten H, Hansman GS. Human norovirus inhibition by a human milk oligosaccharide. Virology. (2017) 508:81-9. doi: 10.1016/j.virol.2017.04.032

200. Murphy K, Curley D, O'callaghan TF, O'shea CA, Dempsey EM, O'toole PW, et al. The composition of human milk and infant faecal microbiota over the first three months of life: a pilot study. Sci Reports. (2017) 7:40597. doi: 10.1038/srep40597

201. Pannaraj PS, Li F, Cerini C, Bender J. M., Yang S, Rollie A, et al. Association between breast milk bacterial communities and establishment and development of the infant gut microbiome. JAMA Pediatr. (2017) 171:647-54. doi: 10.1001/jamapediatrics.2017.0378

202. Kvistgaard AS, Pallesen LT, Arias CF, López S, Petersen TE, Heegaard CW, et al. Inhibitory effects of human and bovine milk constituents on rotavirus infections. J Dairy Sci. (2004) 87:4088-96. doi: 10.3168/jds.S0022-0302(04)73551-1

203. Turin CG, Ochoa TJ. The role of maternal breast milk in preventing infantile diarrhea in the developing world. Curr Trop Med Reports. (2014) 1:97-105. doi: 10.1007/s40475-014-0015-x

204. Prameela KK, Paediatrics F. Breastfeeding - Anti-viral potential and relevance to the influenza virus pandemic. Med J Malaysia. (2011) 66:166-9.

205. Lewandowska-Polak A, Brauncajs M, Jarzebska M, Pawełczyk M, Kurowski M, Makowska J, et al. Original research article Parainfluenza virus infection enhances NSAIDs-induced inhibition of PGE2 generation and COX-2 expression in human airway epithelial cells. Adv Med Sci. (2019) 64:338-43. doi: 10.1016/j.advms.2019.04.004

206. Valenti P, Antonini G. Lactoferrin: an important host defence against microbial and viral attack. Cell Mol Life Sci. (2005) 62:2576-87. doi: 10.1007/s00018-005-5372-0

207. Pandey RP, Kim DH, Woo J, Song J, Jang SH, Kim JB, et al. Broadspectrum neutralization of avian influenza viruses by sialylated human milk oligosaccharides: in vivo assessment of $3^{\prime}$-sialyllactose against $\mathrm{H} 9 \mathrm{~N} 2$ in chickens. Sci Rep. (2018) 8:2563. doi: 10.1038/s41598-018-20955-4

208. Lawrence RM, Lawrence RA. Since January 2020 Elsevier Has Created a COVID-19 Resource Centre with Free Information in English and Mandarin on the Novel Coronavirus COVID- 19. The COVID-19 Resource 
Centre Is Hosted on Elsevier Connect, the Company's Public News and Information (2020).

209. Conzelmann C, Zou M, Gro,ß R, Harms M, Röcker A, Riedel CU, et al. Storage-dependent generation of potent anti-ZIKV activity in human breast milk. Viruses. (2019) 11:591. doi: 10.3390/v11070591

210. Mullins E, Evans D, Viner RM, O'Brien P, Morris E. Coronavirus in pregnancy and delivery: rapid review. Ultrasound Obstetrics Gynecol. (2020) 55:586-92. doi: 10.1002/uog.22014

211. Helmy YA, Fawzy M, Elaswad A, Sobieh A, Kenney SP, Shehata AA. The COVID-19 Pandemic: A comprehensive review of taxonomy, genetics, epidemiology, diagnosis, treatment, and control. J Clin Med. (2020) 9:1225. doi: $10.3390 / \mathrm{jcm} 9041225$

212. Decaro N, Mari V, Elia G, Addie DD, Camero M, Lucente MS, et al. Recombinant canine coronaviruses in dogs, Europe. Emerg Infect Dis. (2010) 16:41-7. doi: 10.3201/eid1601.090726

213. Du L, He Y, Zhou Y, Liu S, Zheng BJ, Jiang S. The spike protein of SARS$\mathrm{CoV}$ - A target for vaccine and therapeutic development. Nat Rev Microbiol. (2009) 7:226-36. doi: 10.1038/nrmicro2090

214. Chan JFW, Kok KH, Zhu Z, Chu H, To KKW, Yuan S, et al. Genomic characterization of the 2019 novel human-pathogenic coronavirus isolated from a patient with atypical pneumonia after visiting Wuhan. Emerg Microbes Infect. (2020) 9:221-36. doi: 10.1080/22221751.2020.1719902

215. Li JY, You Z, Wang Q, Zhou ZJ, Qiu Y, Luo R, et al. The epidemic of 2019-novel-coronavirus (2019-nCoV) pneumonia and insights for emerging infectious diseases in the future. Microbes Infect. (2020) 22:80-5. doi: 10.1016/j.micinf.2020.02.002

216. Zhou P, Yang XL, Wang X. G., Hu B, Zhang L, Zhang W, et al. A pneumonia outbreak associated with a new coronavirus of probable bat origin. Nature. (2020) 579:270-3. doi: 10.1038/s41586-020-2012-7

217. Muldoon, KM, Fowler, KB, Pesch, MH, et al. SARS-CoV-2: Is it the newest spark in the TORCH? J Clin Virol. (2020) 127:104372. doi: 10.1016/j.jcv.2020.104372

218. Stumpfe FM, Titzmann A, Schneider MO, Stelzl P, Kehl S, Fasching PA, et al. SARS-CoV-2 infection in pregnancy - a review of the current literature and possible impact on maternal and neonatal outcome. Geburtshilfe Frauenheilkd. (2020) 80:380-90. doi: 10.1055/a-1134-5951

219. Schwartz DA, Graham AL. Potential maternal and infant outcomes from coronavirus 2019-NCOV (SARS-CoV-2) infecting pregnant women: Lessons from SARS. MERS, and other human coronavirus infections. Viruses. (2020) 12:194. doi: 10.3390/v12020194

220. Rasmussen SA, Smulian JC, Lednicky JA, Wen TS, Jamieson DJ. Coronavirus Disease 2019 (COVID-19) and pregnancy: what obstetricians need to know. Am J Obstetrics Gynecol. (2020) 222:415-426. doi: 10.1016/j.ajog.2020.02.017

221. Schwartz DA. An analysis of 38 pregnant women with COVID-19, their newborn infants, and maternal-fetal transmission of SARS-CoV-2: Maternal coronavirus infections and pregnancy outcomes. Arch Pathol Lab Med. (2020) 144:799-805. doi: 10.5858/arpa.2020-0901-SA

222. Chen H, Guo J, Wang C, Luo F, Yu X, Zhang W, et al. Clinical characteristics and intrauterine vertical transmission potential of COVID-19 infection in nine pregnant women: a retrospective review of medical records. Lancet. (2020) 395:809-15. doi: 10.1016/S0140-6736(20)30360-3

223. Liu W, Wang Q, Zhang Q, Chen L. Coronavirus disease 2019 (COVID-19) during pregnancy: a case series. (2020) 2020020373.

224. Zhu H, Wang L, Fang C, Peng S, Zhang L, Chang G, et al. Clinical analysis of 10 neonates born to mothers with 2019-nCoV pneumonia. Translational Pediatrics. (2020) 9:51-60. doi: 10.21037/tp.2020. 02.06

225. Dashraath P, Wong JLJ, Lim MXK, Lim LM, Li S, Biswas A, et al. Coronavirus disease 2019 (COVID-19) pandemic and pregnancy. Am J Obstet Gynecol. (2020) 222:521-31. doi: 10.1016/j.ajog.2020.03.021

226. Zeng L, Xia S, Yuan W, Yan K, Xiao F, Shao J, et al. Neonatal earlyonset infection with SARS-CoV-2 in 33 Neonates Born to Mothers with COVID-19 in Wuhan, China. JAMA Pediatrics. (2020) 174:722-5. doi: 10.1001/jamapediatrics.2020.0878

227. Zeng H, Xu C, Fan J, Tang Y, Deng Q, Zhang W, et al. Antibodies in infants born to mothers with COVID-19 pneumonia. JAMA. (2020) 323:1848-9. doi: 10.1001/jama.2020.4861
228. Ah EG. Asploro Journal of Biomedical and Clinical Case Reports COVID19 and Breastfeeding. Asp Biomed Clin Case Rep. (2020) 3:102-5. doi: 10.36502/2020/ASJBCCR.6194

229. Gilat R, Haunschild ED, Tauro T, Cole BJ. Since January 2020 elsevier has created a COVID-19 resource centre with free information in English and Mandarin on the Novel Coronavirus COVID-. Ann Oncol. (2020).

230. American Academy of Pediatrics (2020). AAP Issues Guidance on Breastfeeding during COVID-19 Pandemic. https://www.aappublications. org/news/2020/04/23/covid19breastfeeding042320

231. Yang B, Chuang $H$, Chen RF. Protection from viral infections by human milk oligosaccharides: Direct blockade and indirect modulation of intestinal ecology and immune reactions. Open Glycosci. (2012) 5:19-25. doi: $10.2174 / 1875398101205010019$

232. Lang J, Yang $N$, Deng J, Liu K, Yang $P$, Zhang $G$, et al. Inhibition of SARS pseudovirus cell entry by lactoferrin binding to heparan sulfate proteoglycans. PLoS ONE. (2011) 6:102-5. doi: 10.1371/journal.pone.0023710

233. Reghunathan R, Jayapal M, Hsu LY, Chng HH, Tai D, Leung BP, et al. Expression profile of immune response genes in patients with severe acute respiratory syndrome. BMC Immunol. (2005) 6:2. doi: 10.1186/1471-2172-6-2

234. Belting M. Heparan sulfate proteoglycan as a plasma membrane carrier. Trends Biochem Sci. (2003) 28:145-51. doi: 10.1016/S0968-0004(03)00031-8

235. Li W, Moore MJ, Vasllieva N, Sui J, Wong SK, Berne MA, et al. Angiotensin-converting enzyme 2 is a functional receptor for the SARS coronavirus. Nature. (2003) 426:450-4. doi: 10.1038/nature02145

236. Labò N, Ohnuki H, Tosato G. (2020) Vasculopathy and Coagulopathy Associated with SARS-CoV-2 Infection. Cells. NLM (Medline). doi: $10.3390 /$ cells 9071583

237. Rothan HA, Byrareddy SN. The epidemiology and pathogenesis of coronavirus disease (COVID-19) outbreak. J Autoimmunity. (2020) 109:102433. doi: 10.1016/j.jaut.2020.102433

238. Hasan A, Paray BA, Hussain A, Qadir FA, Attar F, Aziz FM, et al. A review on the cleavage priming of the spike protein on coronavirus by angiotensin-converting enzyme-2 and furin. J Biomol Structure Dynamics. (2020). doi: 10.1080/07391102.2020.1754293

239. Mille JK, Whittaker GR. Host cell entry of Middle East respiratory syndrome coronavirus after two-step, furin-mediated activation of the spike protein. Proc Natl Acad Sci USA. (2014) 111:15214-9. doi: 10.1073/pnas. 1407087111

240. van Keulen BJ, Romijn M, Bondt A, van der Straten K, den Boer MA, Bosch BJ, et al. Breastmilk: a source of SARS-CoV-2 specific IgA Antibodies. SSRN Electronic J. (2020). doi: 10.2139/ssrn.3633123

241. Lebrão CW, Cruz MN, Silva MHD, Dutra LV, Cristiani C, Affonso Fonseca FL, et al. Early Identification of IgA Anti-SARSCoV-2 in Milk of Mother With COVID-19 Infection. J Hum Lact Sep. (2020) 28:890334420960433. doi: $10.1177 / 0890334420960433$

242. Pace RM, Williams JE, Järvinen KM, Belfort MB, Pace CD, Lackey KA, et al. COVID-19 and human milk: SARS-CoV-2, antibodies, neutralizing capacity. medRxiv. (2020) 2020.09.16.20196071. doi: 10.1101/2020.09.16.20196071

243. Fan H, Hong B, Luo Y, Peng Q, Wang L, Jin X, et al. The effect of whey protein on viral infection and replication of SARS-CoV-2 and pangolin coronavirus in vitro. Signal Transduction Targeted Therapy. (2020) 5, 275. doi: 10.1038/s41392-020-00408-z

244. Guzzi, PH, Mercatelli, D, Ceraolo, C, et al. Master regulator analysis of the SARS-CoV-2/Human Interactome. J Clin Med. (2020) 9:982doi: $10.3390 / \mathrm{jcm} 9040982$

245. Choudhury A, Mukherjee S. In silico studies on the comparative characterization of the interactions of SARS-CoV-2 spike glycoprotein with ACE-2 receptor homologs and human TLRs. J Med Virol. (2020) 92:2105-13. doi: $10.1002 / j m v .25987$

246. Mukherjee S, Huda S, Sinha Babu SP. Toll-like receptor polymorphism in host immune response to infectious diseases: a review. Scand J Immunol. (2019) 90:e12771. doi: 10.1111/sji.12771

247. Mukherjee S, Karmakar S, Babu SPS. TLR2 and TLR4 mediated host immune responses in major infectious diseases: a review. Brazilian J Infect Dis. (2016) 20:193-204. doi: 10.1016/j.bjid.2015.10.011 
248. Brandão SCS, Ramos J, de OX, Dompieri LT, Godoi, E. T. A. M., et al. Is Tolllike receptor 4 involved in the severity of COVID-19 pathology in patients with cardiometabolic comorbidities? Cytokine Growth Factor Rev. (2020) 5:19-25. doi: 10.1016/j.cytogfr.2020.09.002

249. Sohn KM, Lee SG, Kim HJ, Cheon S, Jeong H, Lee J, et al. COVID-19 patients upregulate toll-like receptor 4-mediated inflammatory signaling that mimics bacterial sepsis. J Korean Med Sci. (2020) 35:e343. doi: $10.3346 / \mathrm{jkms} .2020 .35 . \mathrm{e} 343$

250. Angelopoulou A, Alexandris N, Konstantinou E, Mesiakaris K, Zanidis C, Farsalinos K, et al. Imiquimod - A toll like receptor 7 agonist - Is an ideal option for management of COVID 19. Environ Res. (2020) 188:109858. doi: 10.1016/j.envres.2020.109858

251. Totura AL, Whitmore A, Agnihothram S, Schäfer A, Katze MG, Heise MT, et al. Toll-like receptor 3 signaling via TRIF contributes to a protective innate immune response to severe acute respiratory syndrome coronavirus infection. MBio. (2015) 6:1-14. doi: 10.1128/mBio.00638-15

252. Catanzaro, M, Fagiani, F, Racchi, M, et al. Immune response in COVID-19: addressing a pharmacological challenge by targeting pathways triggered by SARS-CoV-2. Signal Transduct Target Ther. (2020) 29:5:84. doi: 10.1038/s41392-020-0191-1

253. Gong J, Dong H, Xia Q, Huang Z, Wang D, Zhao Y, et al. Correlation analysis between disease severity and inflammation-related parameters in patients with COVID-19 Pneumonia. (2020). doi: 10.1101/2020.02.25.20025643

254. Fanelli V, Vlachou A, Ghannadian S, Simonetti U, Slutsky AS, Zhang H. Acute respiratory distress syndrome: NEw definition, current and future therapeutic options. J Thoracic Dis. (2013) 5:326-34. doi: 10.3978/j.issn.2072-1439.2013.04.05

255. Horie S, Gonzalez HE, Laffey JG, Masterson CH. Cell therapy in acute respiratory distress syndrome. J Thoracic Dis. (2018) 10. doi: $10.21037 /$ jtd.2018.08.28

256. DeDiego ML, Nieto-Torres JL, Regla-Nava JA, Jimenez-Guardeno J. M., Fernandez-Delgado R, Fett C, et al. Inhibition of NF- B-mediated inflammation in severe acute respiratory syndrome coronavirus-infected mice increases survival. J Virol. (2014) 88:913-24. doi: 10.1128/JVI.02576-13

257. Bradley LM, Douglass MF, Chatterjee D, Akira S, Baaten BJG. Matrix metalloprotease 9 mediates neutrophil migration into the airways in response to influenza virus-induced toll-like receptor signaling. PLoS Pathog. (2012) 8:e1002641. doi: 10.1371/journal.ppat.1002641

258. Yasui K, Baba A, Iwasaki Y, Kubo T, Aoyama K, Mori T, et al. Neutrophilmediated inflammation in respiratory syncytial viral bronchiolitis. Pediatrics Int. (2005) 47:190-5. doi: 10.1111/j.1442-200x.2005.02039.x

259. Yang WL, Sharma A, Zhang F, Matsuo S, Wang Z, Wang H, et al. Milk fat globule epidermal growth factor-factor 8-derived peptide attenuates organ injury and improves survival in sepsis. Critical Care. (2015) 19:375. doi: 10.1186/s13054-015-1094-3

260. Geng YJ, Wei ZY, Qian HY, Huang J, Lodato R, Castriotta RJ. Pathophysiological characteristics and therapeutic approaches for pulmonary injury and cardiovascular complications of coronavirus disease 2019. Cardiovasc Pathol. (2020) 47:107228. doi: 10.1016/j.carpath.2020.107228

261. McGonagle D, Sharif K, O'Regan A, Bridgewood C. The role of cytokines including Interleukin-6 in COVID-19 induced pneumonia and macrophage activation syndrome-like disease. Autoimmun Rev. (2020) 19:102537. doi: 10.1016/j.autrev.2020.102537

262. Abassi Z, Knaney Y, Karram T, Heyman SN. The lung macrophage in SARS-CoV-2 infection: a friend or a foe? Front Immunol. (2020) 11:1312. doi: 10.3389/fimmu.2020.01312

263. Cavalli G, De Luca G, Campochiaro C, Della-Torre E, Ripa M, Canetti $\mathrm{D}$, et al. Interleukin-1 blockade with high-dose anakinra in patients with COVID-19, acute respiratory distress syndrome, and hyperinflammation: a retrospective cohort study. Lancet Rheumatol. (2020) 2:e325-31. doi: 10.1016/S2665-9913(20)30127-2

264. Zhang Y, Li J, Zhan Y, Wu L, Yu X, Zhang W, et al. Analysis of serum cytokines in patients with severe acute respiratory syndrome. Infect Immun. (2004) 72:4410-5. doi: 10.1128/IAI.72.8.4410-4415.2004

265. Wu C, Hu X, Song J, Du C, Xu J, Yang D, et al. Heart injury signs are associated with higher and earlier mortality in coronavirus disease 2019 (COVID-19). (2020).
266. Buja LM, Zehr B, Lelenwa L, Ogechukwu E, Zhao B, Dasgupta A, et al. Clinicopathological complexity in the application of the universal definition of myocardial infarction. Cardiovascular Pathol. (2020) 44:107153. doi: 10.1016/j.carpath.2019.107153

267. Wan S, Yi Q, Fan S, Lv J, Zhang X, Guo L, et al. Characteristics of lymphocyte subsets and cytokines in peripheral blood of 123 hospitalized patients with 2019 novel coronavirus pneumonia (NCP). (2020). doi: $10.1101 / 2020.02 \cdot 10.20021832$

268. Ouchi N, Walsh K. Adiponectin as an anti-inflammatory factor. Clinica Chimica Acta. (2007) 380:24-30. doi: 10.1016/j.cca.2007.01.026

269. Choi KM, Ryu OH, Lee KW, Kim HY, Seo JA, Kim SG, et al. Serum adiponectin, interleukin-10 levels and inflammatory markers in the metabolic syndrome. Diabetes Res Clin Pract. (2007) 75:235-40. doi: 10.1016/j.diabres.2006. 06.019

270. Zheng L, Riehl TE, Stenson WF. Regulation of colonic epithelial repair in mice by toll-like receptors and hyaluronic acid. Gastroenterology. (2009) 137:2041-51. doi: 10.1053/j.gastro.2009.08.055

271. Bollyky PL, Wu RP, Falk BA, Lord JD, Long SA, Preisinger A, et al. ECM components guide IL-10 producing regulatory T-cell (TR1) induction from effector memory T-cell precursors. Proc Natl Acad Sci USA. (2011) 108:793843. doi: $10.1073 /$ pnas. 1017360108

272. Maheshwari A, Kelly DR, Nicola T, Ambalavanan N, Jain SK, Murphyullrich J, et al. TGF- $\beta 2$ suppresses macrophage cytokine production and mucosal inflammatory responses in the developing intestine. Gastroenterology. (2011) 140:242-53. doi: 10.1053/j.gastro.2010. 09.043

273. Nakanishi K, Yoshimoto T, Tsutsui H, Okamura H. Interleukin-18 is a unique cytokine that stimulates both Th1 and Th2 responses depending on its cytokine milieu. Cytokine Growth Factor Rev. (2001) 12:53-72. doi: 10.1016/S1359-6101(00)00015-0

274. Xu D, Trajkovic V, Hunter D, Leung BP, Schulz K, Alastair Gracie J, et al. IL-18 induces the differentiation of Th1 or Th2 cells depending upon cytokine milieu and genetic background.. Eur J Immunol. (2000) 30:3147-56. doi: 10.1002/1521-4141(200011)30:11<3147::AID-IMMU3147>3.0.CO;2-J

275. Kanai $T$, Watanabe $M$, Okazawa $A$, Sato $T$, Hibi $T$. Interleukin18 and Crohn's disease. Digestion. (2001) 63(Suppl. 1):37-42. doi: $10.1159 / 000051909$

276. Elison E, Vigsnaes LK, Krogsgaard LR, Rasmussen J, Sørensen N, McConnell $\mathrm{B}$, et al. Oral sup- plementation of healthy adults with $2^{\prime}-\mathrm{O}$-fucosyllactose and lacto- $\mathrm{N}$-neotetraose is well tolerated and shifts the intestinal microbiota. Br J Nutr. (2016) 116:1356-68. doi: 10.1017/S00071145160 03354

277. Emami CN, Chokshi N, Wang JJ, Guner Y, Goth K, Wang et al. Grishin, A, Ford HR. Role of interleukin-10 in the pathogenesis of necrotizing enterocolitis. Am J Surg. (2012) 203:428-35. doi: 10.1016/j.amjsurg.2011.08.016

278. Klok FA, den Exter PL, Huisman MV, Eikenboom J. [Dealing with COVID19-associated coagulopathy]. Nederlands Tijdschrift Voor Geneeskunde. (2020) 164. Retrieved from http://www.ncbi.nlm.nih.gov/pubmed/32395964

279. Zhang Y, Xiao M, Zhang S, Xia P, Cao W, Jiang W, et al. Coagulopathy and Antiphospholipid Antibodies in Patients with Covid-19. N Engl J Med. (2020) 382:e38. doi: 10.1056/NEJMc2007575

280. Sardu C, Gambardella J, Morelli MB, Wang X, Marfella R, Santulli G. Hypertension, thrombosis, kidney failure, and diabetes: is COVID-19 an endothelial disease? A comprehensive evaluation of clinical and basic evidence. J Clin Med. (2020) 9:1417. doi: 10.3390/jcm9051417

281. Varga Z, Flammer AJ, Steiger P, Haberecker M, Andermatt R, Zinkernagel AS, et al. Endothelial cell infection and endotheliitis in COVID-19. Lancet. (2020) 395:1417-8. doi: 10.1016/S0140-6736(20)30937-5

282. Matacic C. Blood vessel injury may spur disease's fatal second phase. Science. (2020) 368:1039-40. doi: 10.1126/science.368.6495.1039

283. Wise J. A third of covid-19 patients admitted to UK hospitals die. BMJ. (2020) 369:m1794. doi: 10.1136/bmj.m1794

284. Yazji I, Sodhi CP, Lee EK, Good M, Egan CE, Afrazi A, et al. Endothelial TLR4 activation impairs intestinal microcirculatory perfusion in necrotizing enterocolitis via eNOS-NO-nitrite signaling. Proc Natl Acad Sci USA. (2013) 110:9451-6. doi: 10.1073/pnas.1219997110 
285. Good M, Sodhi CP, Yamaguchi Y, Jia H, Lu P, Fulton WB, et al. The human milk oligosaccharide $2^{\prime}$-fucosyllactose attenuates the severity of experimental necrotising enterocolitis by enhancing mesenteric perfusion in the neonatal intestine. British J Nutr. (2016) 116:1175-87. doi: 10.1017/S0007114516002944

286. Zhao QJ, Yu YB, Zuo XL, Dong YY, Li YQ. Milk fat globule-epidermal growth factor 8 is decreased in intestinal epithelium of ulcerative colitis patients and thereby causes increased apoptosis and impaired wound healing. Mol Med. (2012) 18:497-506. doi: 10.2119/molmed.2011.00369

287. Frey H, Schroeder N, Manon-Jensen T, Iozzo RV, Schaefer L. Biological interplay between proteoglycans and their innate immune receptors in inflammation. FEBS J. (2013) 280, 2165-79. doi: 10.1111/febs.12145

288. Voigt J, Driver VR. Hyaluronic acid derivatives and their healing effect on burns, epithelial surgical wounds, and chronic wounds: a systematic review and meta-analysis of randomized controlled trials. Wound Repair Regeneration. (2012) 20:317-31. doi: 10.1111/j.1524-475X.2012.00777.x

289. Clark JA, Lane RH, Maclennan NK, Holubec H, Dvorakova K, Halpern MD, et al. Epidermal growth factor reduces intestinal apoptosis in an experimental model of necrotizing enterocolitis. Am J Physiol Gastrointest Liver Physiol. (2005) 288:G755-62. doi: 10.1152/ajpgi.00172.2004

290. Knott AW, Juno RJ, Jarboe MD, Profitt SA, Thoerner JC, Erwin CR, et al. EGF receptor signaling a ects bcl-2 family gene expression and apoptosis after massive small bowel resection. J Pediatr Surg. (2003) 38:875-80. doi: 10.1016/S0022-3468(03)00114-3

291. Kaingade PM, Somasundaram I, Nikam AB, Sarang SA, Patel JS. Assessment of growth factors secreted by human breastmilk mesenchymal stem cells. Breastfeeding Med. (2016) 11:26-31. doi: 10.1089/bfm.2015.0124
292. Kaingade PM, Somasundaram I, Nikam AB, Sarang SA, Patel JS. Breastmilkderived mesenchymal stem cells in vitro are likely to be mediated through epithelial-mesenchymal transition. Breastfeed Med. (2016) 11:152. doi: 10.1089/bfm.2016.0023

293. Stonesifer C, Corey S, Ghanekar S, Diamandis Z, Acosta SA, Borlongan CV. Stem cell therapy for abrogating stroke-induced neuroinflammation and relevant secondary cell death mechanisms. Progress Neurobiol. (2017) 158:94-131. doi: 10.1016/j.pneurobio.2017. 07.004

294. Fox A, Marino J, Amanat F, Krammer F, Hahn-Holbrook J, ZollaPazner S, et al. Robust and specific secretory IgA AGAINST SARS-CoV-2 detected in human Milk. IScience. (2020) 23:101735. doi: 10.1016/j.isci.2020. 101735

295. Newmark LM. SARS-CoV-2 Research Highlights the Importance of Human Milk Immunobiology. International Milk Genomics Consortium (2020)

Conflict of Interest: The authors declare that the research was conducted in the absence of any commercial or financial relationships that could be construed as a potential conflict of interest.

Copyright (C) 2021 Quitadamo, Comegna and Cristalli. This is an open-access article distributed under the terms of the Creative Commons Attribution License (CC BY). The use, distribution or reproduction in other forums is permitted, provided the original author(s) and the copyright owner(s) are credited and that the original publication in this journal is cited, in accordance with accepted academic practice. No use, distribution or reproduction is permitted which does not comply with these terms. 